\title{
Progress in Use of Natural Products and Their Active Components against Helicobacter pylori
}

\author{
Alejandro Venegas ${ }^{1 *}$, Jorge Hantar Touma ${ }^{1}$, Jessica Bravo1, Guillermo Perez-Perez ${ }^{2}$ \\ ${ }^{1}$ Centro de Investigación Biomédica, Facultad de Medicina, Universidad Diego Portales, Santiago, Chile \\ ${ }^{2}$ Departments of Medicine and Microbiology, New York Langone Medical Center, NYU, New York, USA \\ Email: ^alejandro.venegas@udp.cl, jorge.touma@mail.udp.cl, jessica.bravo@mail.udp.cl, guillermo.perez-perez@nyumc.org
}

How to cite this paper: Venegas, A., Touma, J.H., Bravo, J. and Perez-Perez, G. (2016) Progress in Use of Natural Products and Their Active Components against Helicobacter pylori. Advances in Microbiology, 6, 1091-1129.

http://dx.doi.org/10.4236/aim.2016.614101

Received: November 9, 2016

Accepted: December 23, 2016

Published: December 28, 2016

Copyright $\odot 2016$ by authors and Scientific Research Publishing Inc. This work is licensed under the Creative Commons Attribution International License (CC BY 4.0).

http://creativecommons.org/licenses/by/4.0/

\begin{abstract}
Helicobacter pylori is considered the main etiological agent of gastritis, ulcers, and gastric carcinoma. It colonizes human gastric mucosa quite efficiently. Fifty $\%$ of the world population is actually infected. Since $H$. pylori discovery in 1982, it is well known the sensitivity of several $H$. pylori strains to a number of antibiotics when these are assayed in vitro. However, eradication therapies with a single antibacterial agent have failed. Recently, triple, quadruple, sequential, concomitant and hybrid therapies which include antibiotics and a proton pump inhibitor show improved eradication rate and low side effects. However, new problems have emerged. Antimicrobial resistance to the common antibiotics used has become a problem in both developed and developing countries. In particular, H. pylori clarithromycin- and metronidazole-resistant strains are a major problem in countries where $H$. pylori is highly prevalent. Thus, the widespread use of antibiotics is not economically feasible and might increase difficulties in the treatment of $H$. pylori. At present, there are no vaccines available in the market. As an alternative, effective non-antibiotic compounds should be highly desirable since their use may be safer and suitable to eradicate $H$. pylori. The first step in this direction has been to study the effect of medicinal herbs and natural products, such as green tea, ginseng, garlic, propolis, and probiotics, then identify their active components such as polyphenols, antioxidants, purify them, and finally test them using in vitro and in vivo $H$. pylori growth assays. Some of them have been quite effective. The topics related to alternative therapies for $H$. pylori infections and current status of their use will be discussed in the present review.
\end{abstract}

\section{Keywords}

H. pylori Growth Inhibition, Natural Products, Herb Infusions, Phytochemicals, Purified Antimicrobial Compounds 


\section{Introduction}

Although antibiotics are usually effective in the treatment of Helicobacter pylori infection their success is limited. H. pylori causes lifelong chronic gastritis, which can lead to peptic ulcers, mucosa-associated lymphoid tissue (MALT) lymphoma and gastric cancer [1]. In the past, $H$. pylori infections were associated with eradication rate greater than $80 \%$ [2] [3] [4]. However, antibiotic treatments induce resistance mostly due to interruption of treatment doses. Also, antibiotics are expensive and promote adverse side effects.

At present there is no large scale production of an effective vaccine against $H$. pylori available at the market [5]; therefore, other alternative approaches such as natural products, the central topic of this review, as well as phage therapies tested on Campylobacter species [6] and phototherapy [7] should be tried.

Active compounds including antioxidants from plants and other $H$. pylori natural sources and urease inhibitors [8] are valid alternatives to control gastric colonization. The use of natural products and antioxidants may improve antibiotic treatment efficacy and reduce unwanted side effects. Few reviews are available on this subject [8] [9] [10].

\section{Natural Tea-Type Infusions}

\subsection{Green Tea}

It has been early reported that tea catechins have antibacterial activity against some food-borne pathogens [11]. In addition, a variety of beneficial activities on human health has been described in tea catechins which correspond to almost $15 \%$ of green tea referred as dry weight [12]. It has been quite interesting to search for tea catechins antibacterial properties for the eradication of $H$. pylori. The study of Mabe et al., 2009 [13] has been focused on this aspect. In vitro studies to estimate the Minimal Inhibitory Concentration (MIC) values and the in vivo effects of the gastric mucosal injury were done using the Mongolian gerbil as an animal model and H. pylori ATCC $43504\left(10^{8}\right.$ $\mathrm{CFU}$ or colony forming unit) as the inoculating strain. They identified four catechins: epicatechin (EC), epigallocatechin (EGC), epicatechin gallate (ECg, and epigallo-catechin gallate (EGCg), being EGCg the most effective in vitro (MIC range $=1-64 \mathrm{ug} / \mathrm{ml}$ ) when assayed on 110 clinical isolates. In contrast, in vivo studies using tea catechins showed antibacterial activity but low eradication rate, ranging $10 \%-36.4 \%$. It was proposed that $\mathrm{pH}$ dependency of catechin antibacterial activity and short gastric transit time of these agents were responsible for producing such low eradication rates.

A more recent study on tea polyphenols [14] from 9 tea extracts including 4 different processed tea types (white, green, oolong and black) were tried on $H$. pylori to evaluate growth inhibition. Aqueous extraction by boiling during 5 min was more effective than $2 \mathrm{~min}$. In this last case, only 2 teas showed inhibition on this bacterium. The inhibition by polyphenols is not due to inhibition of proline oxidation via proline dehydrogenase. In addition, the extracts did not affect the beneficial lactic bacteria. Gallic acid, quercetin, caffeine and tea catechins (catechin, epicatechin, and epigallocatechin), are present in all tea samples. These authors suggested that tea can be used as a cheap dietary com- 
plement to fighting $H$. pylori gastric diseases.

Recently, studies using green tea as therapeutic agent showed that using CSA (comparative screening assay), a score reduction higher than $8 \times 10^{4} \mathrm{CFU}$ (colony forming unit) was found in more than $60 \%$ of the positive strains by green tea $(81.5 \%)$, which also possess additional beneficial properties, e.g. antioxidant, anti-inflammatory and antitumor activities. Therefore, these plants may have a beneficial use as prophylactic agents against or adjuvants in the therapy of $H$. pylori infection [15] [16].

\subsection{Honey and Teas}

In a study done by Boyanova et al., (2015) [17], authors evaluated the influence of dietary and demographic factors and some habits on the prevalence of $H$. pylori infection in 150 dyspeptic patients examined by endoscopy and urea breath tests. Positivity rate was lower (50.6\%) in patients consuming honey $\geq 1$ day weekly compared with the remainder $(70.8 \%)$ and in those consuming green/black tea $\geq 1$ day weekly (45.2\%) compared with the other patients (64.8\%). Logistic regression confirmed that the factors associated with significantly lower $H$. pylori positivity rate were the consumption of honey (odds ratio [OR], 0.38; 95\% confidence interval [CI], 0.19 - 0.78) and green/black tea (OR, 0.45; 95\% CI, $0.21-0.95)$. Therefore, honey and green/black tea intake are associated with reduced prevalence of $H$. pylori infections.

\subsection{Propolis}

Propolis (bee glue) is a resinous product collected by honeybees from plants. The main sources of propolis are the buds of poplars [18]. If suitable plant sources are not available for honey bees, toxic substances may be included in the propolis. Bee glue contains resins such as flavonoids and derivatives of phenolic acids, wax, essential oils, pollen and organic compounds [19]. Propolis has antimicrobial, antioxidant, anti-inflammatory and anesthetic properties. In addition, synergistic effect with antibacterial agents has been described [20]. Bee glue affects cytoplasmic membrane and bacterial motility [21]. In general, Propolis presents bacteriostatic activity against different bacterial genera but can be bactericidal at higher doses [22]. Brazilian propolis has been described as effective hepatoprotective agent and having anti- $H$. pylori activity. Recently, Bulgarian propolis was tested in vitro on several $H$. pylori strains, using different methods [15]. They used agar-well diffusion, agar dilution and disc diffusion methods to evaluate the antimicrobial activity of a $30 \%$ ethanolic extract of Bulgarian propolis. These authors found a strong dose-dependent activity against most of $H$. pylori strains tested. Although the in vitro effect is promising, further pharmacological and clinical trials are needed to confirm its in vivo activity.

Propolis and Zingiber officinalis (ginger root tea) extracts have demonstrated to be specific for $H$. pylori strains, and also presenting anti-inflammatory, antioxidant and antitumoral activities when employed in traditional medicine [23]. Nostro group evaluated the combined effect of propolis and clarithromycin on $H$. pylori isolates characterized as clarithromycin susceptible and carrying the cagA gene. They found that 
combinations of propolis extracts and clarithromycin, as well as, $Z$. officinalis extracts and clarithromycin presented improved properties to inhibit $H$. pylori growth. Interestingly, the susceptibility to those combinations was independent of the $H$. pylori clarithromycin status. These data showed that these combinations have the potential to control $H$. pylori-associated diseases in patients colonized with clarithromycin resistant strains. Cui et al., (2013) [24] demonstrated that caffeic acid phenethyl ester (CAPE) showed strong inhibitory activity against $H$. pylori peptide deformylase (Hp PDF), which also may account for the anti- $H$. pylori activity of propolis. Moreover, the structure of CAPE is different from the majority of known PDF inhibitors, which are mainly pseudopeptides. CAPE binds at the enzyme active site region without interaction with the catalytic $\mathrm{Co}^{2+}$, which may decrease the interaction between CAPE and other metalloproteins in the human body and hence reduce the possible adverse effect. The authors in this study provided new structural information on the inhibitor-Hp PDF complex, which will allow design new potential anti- $H$. pylori inhibitors and improve the rational drug design. This group reported that CAPE found in propolis, a natural antibiotic from honey bees, had an inhibitory effect on $H$. pylori growth. Previous results had suggested that the main compounds in propolis are phenolic derivatives. Some of these, in particular, CAPE, acting as a competitive inhibitor, reduce the activity of $H$. pylori peptide deformylase (HpPDF). This enzyme is essential for $H$. pylori survival since is required to remove formyl group from the $\mathrm{N}$-terminus of newly synthesized polypeptides. The authors of this paper also demonstrated that CAPE blocks the substrate entrance, avoiding the approach to the HpPDF active site but does not perform as a chelator on HpPDF or disrupt metal-dependent catalysis. This compound could be very helpful as a new drug to control $H$. pylori infections.

A recent study [25] including 15 different ethanolic propolis extracts (EPEs) to treat $H$. pylori was performed. The anti- $H$. pylori and anti-urease activities were evaluated. The total phenolic contents and total flavonoid contents of the EPE were also measured. The agar-well diffusion assay was carried out on $H$. pylori strain $J 99$ and the inhibition zones were measured and compared with standards. All propolis extracts showed high inhibition on $H$. pylori $\mathrm{J99}$, with inhibition halo a diameter ranging from 31.0 to $47.0 \mathrm{~mm}$. $H$. pylori urease inhibitory activity was measured using the phenol-hypochlorite assay. All EPEs showed significant inhibition of the enzyme, with $50 \%$ inhibition concentrations (IC50 values) ranging from 0.260 to $1.525 \mathrm{mg} / \mathrm{ml}$. The degree of inhibition was related to the phenolic content of the EPE. The authors concluded that propolis extract was found to be a good inhibitor that can be used in $H$. pylori treatment to improve human health [25].

\subsection{Ginseng}

Early, in 1987, studies on Ginseng consumption have been reported indicating a reduction of the risk of cancer in diverse organs, including the lip, oral cavity, pharynx, larynx, esophagus, lung, liver, pancreas, ovary, colon, rectum, and stomach, as demonstrated in clinical and epidemiological studies [26] [27]. Based on these findings, Panax 
ginseng has been classified as a "non-organ-specific cancer preventive". However, since the early development and uses of traditional medicinal herbs has been questioned and purified compounds and exact mode of action are required to convince skeptical people. The use of panaceic compounds such as protopanaxatriol has been a prime issue discussed in terms of complementary and alternative medicine.

A study of Bae et al., (2001) [28] showed the inhibitory effect of polyacetylenes and protopanaxatriol, compounds isolated from heated Ginseng extracts (family Araliaceae, Pana) on $H$. pylori growth by in vitro assays. Regarding particular Ginseng compounds tested, panaxytriol, a fatty alcohol, was extremely effective in inhibiting $H$. pylori growth with a MIC value of $50 \mu \mathrm{g} / \mathrm{ml}$. In addition, Ginsenoside $\mathrm{Rh} 1$ and protopanaxatriol (a tetracycle triterpenoid saponin), weakly inhibited $\mathrm{H}+/ \mathrm{K}+$ ATPase from rat stomachs. Red Ginseng roots extracts (RGE) from Panax Ginseng CA Meyer presented antimicrobial or antiadhesion activities against $H$. pylori.

$H$. pylori are capable of inducing gastric inflammation, ulceration, and DNA damage, based on which WHO defined this bacterium as a class I carcinogen. Ginseng root (Panax ginseng C.A. Meyer) presented anti-adhesion or antimicrobial activity against $H$. pylori [29]. These authors evaluated the protective effect of red ginseng extracts (RGE) against cytotoxicity and DNA damage induced by $H$. pylori. RGE significantly reduced both effects measured by comet assay and apoptosis detected by DNA fragmentation. Signaling by ERK1/2 was inactivated, caspase-3 activation reduced and PARP cleavage detected. IL- 8 gene expression was reduced by RGE displaying significant gastroprotective effects, supporting the use of RGE as phytonutrient with medical properties against $H$. pylori infection.

Up-regulations of inflammatory mediators such as IL- $1 \beta$, IL-8, and iNOS have been previously shown in gastric mucosa of $H$. pylori-infected patients with gastric inflammation (gastritis, gastric ulcer). Korean red ginseng is one of the most popular traditional medicines in Korea due to its stimulating effect on the immune system and inhibition on inflammation. The study of Bae et al., (2011) [30] was focused on establishing the effect of Korean RGE on the expression of inflammatory mediators (IL-1 $\beta$, KC [IL-8 homolog], iNOS) induced by $H$. pylori infection in gastric mucosa of Mongolian gerbil. It was found that water extract of Korean RGE inhibited expression of IL- $1 \beta$, $\mathrm{KC}$, and iNOS in gastric mucosa. Also, H. pylori-induced phosphorylation of $\operatorname{I\kappa B} \alpha$, which is required for NF- $\kappa B$ activation, was suppressed at the gerbil gastric epithelium by the Korean RGE treatment. The researchers concluded that Korean RGE would be useful to prevent gastric inflammation induced by the $H$. pylori gastric infection.

However, evidence-based medicine, consisting of large-scale or well designed clinical studies, is still warranted whether Korean red ginseng is to be recognized as an essential therapeutic strategy as an " $H$. pylori-associated gastric cancer preventive". Specifically, comprehensive clinical trials of Korean red ginseng are needed to demonstrate that mucosa regeneration in patients with atrophic gastritis is feasible using Korean red ginseng supplements after the eradication of $H$. pylori infection. Ginseng is a good example of a natural herb and its ubiquitous properties may include the reduction or de- 
lay of inflammation carcinogenesis. Korean red ginseng contains ample amounts of active ginsenosides and it has been demonstrated their effects by in vitro and in vivo studies with positive outcomes [31].

In another study described by Cho et al., (2013) [32] inhibition of NADPH oxidase (source of reactive oxygen species) by Korean RGE was tested. These researchers reported that a source of reactive oxygen species (ROS) reacted at the Jak2/Stat3 pathway, which regulates the expression of inflammatory mediators in $H$. pylori-infected AGS gastric epithelial cells. The infection caused an increase in reactive oxygen species (ROS) and activation of NADPH oxidase and Jak2/Stat3 inducing inflammatory mediator as monocyte chemoattractant protein 1 (MCP-1) and inducible nitric oxide synthase (iNOS) in these cells. Induction of MCP-1 and iNOS in infected AGS was blocked by AG490 inhibitor and RGE. NADPH oxidase was also abolished by RGE by inhibition of membrane translocation of p67phox and p47phox cytosolic subunits of NADPH oxidase. RGE also reduced ROS levels in AGS-infected cells.

$H$. pylori is a major cause of gastric inflammation and gastric carcinoma in humans and Mongolian gerbils which have been used as animal model for gastric cancer. Recently, Bae et al., (2014) [33] investigated whether RGE inhibited H. pylori-induced gastric inflammation in gerbils. A week after intragastric inoculation with $H$. pylori, gerbils were given either a control diet or a diet with $200 \mathrm{mg}$ RGE/gerbil for 6 weeks. Viable $H$. pylori colony count in the stomach was not altered. However, protein levels of KC, (a rodent IL- 8 homolog), IL- $1 \beta$, iNOS and phosphorylation of IкB $\alpha$ normally induced by $H$. pylori in gastric mucosa, were drastically reduced by RGE diet, but lipid peroxide(LPO) level and myeloperoxidase (MPO) activity increased and improved the histological grade of infiltration of polymorphonuclear neutrophils and thus reducing gastric colonization. It was concluded that RGE inhibits $H$. pylori-induced gastric inflammation by suppressing induction of inflammatory mediators (KC, IL- $1 \beta$, iNOS, MPO activity, and LPO level) in $H$. pylori-infected gastric mucosa of gerbils.

A recent meta-analysis [34] established a probable association between Ginseng consumption and lower risk of cancer. In doing this, 6 databases covering from 1990 to 2014 were considered. Based on statistical analyses the relative risks (RRs) with 95\% confidence intervals (CI) were obtained. The study involved 7436 cases and 334.544 participants based on 5 cohort studies, 3 case-control studies and one randomized controlled trial revealing that patients consuming Ginseng had 16\% lower risk of developing cancer $(\mathrm{RR}=0.84 ; 9 \% \mathrm{CI}=0.76-0.92)$. Some studies considered 4 specific types of cancer (colorectal, lung, gastric and liver cancers). As a conclusion, this meta-analysis indicates that ginseng consumption is associated with a reduced risk of cancer and that the effect is not specific to a particular organ.

\subsection{Garlic Compounds}

Garlic (Allium sativum) may provide a suitable source to obtain new drugs with anti- $H$. pylori activities since it have been known for a long time that it has antimicrobial properties [35] [36]. 
Garlic has been frequently used as a traditional treatment for several gastrointestinal infections. Several groups have reported the effect of garlic on $H$. pylori [37] [38]. Some researchers [31] [39] noted the connection between $H$. pylori-associated gastric cancer, and the lower incidence of this cancer among people who usually eat garlic, and tested the hypothesis that garlic might kill $H$. pylori. They made a simple water extract of garlic and then standardized it for thiosulfinate content. Thiosulfinate with allicin (allyl 2-propeno thiosulfinate) being the most abundant antimicrobial garlic members among others, are variable in content, ranging from 2 to about $9 \mathrm{mg}$ per gram of crushed garlic [40]. Forty micrograms of thiosulfinate per $\mathrm{ml}$ of the garlic extract were the minimum dose to inhibit $H$. pylori in the trial. The $40 \mu \mathrm{g} / \mathrm{ml}$ of thiosulfinates equals 4.5 to 20 grams of garlic, which means about 1.5 to 6.5 garlic cloves in a liter of water. Thiosulfinate content is maximized by crushing or blending the fresh cloves but is greatly reduced in dried products or garlic oils. The authors suggested that such a mixture might be an effective treatment for $H$. pylori infection. In addition, direct intragastric effects are feasible because garlic antimicrobials are unaffected by acid environments [40]. Moreover, gastric juice enhances the antimicrobial activity of garlic constituents [41]. Allicin was identified as the main antimicrobial compound provided by garlic. Allicin is formed catalytically when garlic cloves are crushed and the enzyme allicinase of the bundle sheath cells meets its substrate, allicin, which is released from mesophyll cells [40]. Most common commercial preparations of garlic are garlic powder (GP) and garlic oil (GO). GP is prepared from sliced, dried and pulverized garlic cloves which form allicin after addition of water. GO is produced by heating of crushed garlic cloves to $100^{\circ} \mathrm{C}$ and collection of this vapor is recovered as a distillate [42]. This process is equivalent to cooking crushed garlic and allicin converts into diallyl sulfide (DADS) and other derivatives.

A study of O'Gara et al., (2000) [43] revealed that anti-H. pylori activity was considerably greater for the GO (MIC values ranged 8-62-fold lower) than GP and large differences were detected among diallyl derivatives. Allicin, the only diallyl compound and major thiosulfinate formed from GP were more inhibitory (MIC range $6-12 \mu \mathrm{g} / \mathrm{ml}$ ) than any DAS (Diallyl sulfide), except DATTS (Diallyl thiosulfinates) (MIC range 3 - 6 $\mu \mathrm{g} / \mathrm{ml})$. Following $H$. pylori time course viability it was noted that after 1-hour exposures to $129 \mu \mathrm{g} / \mathrm{ml}$ of GO, $H$. pylori motility was greatly reduced, bacterial clumping increased, and 25\% - 50\% of cells presented morphology changes to coccoid forms. By 6 hours most cells were coccoids. These cells are no longer viable.

The common use of dietary garlic to fight infections and the medicinal use of GO to treat various diseases [40] suggest that the systemic distribution of garlic compounds is quite efficient. GO sulfides are easily absorbed. Some of them such as DADS (Diallyl disulfides) have significant half-lives in blood and the allyl methyl sulfide [44], a major allicin metabolite derivative, is persistent in a way that it can be detected on the breath.

In the search for the target of these garlic compounds Chung et al., (1998) [45] described the reduction in the activity of arylamine $\mathrm{N}$-acetyl transferase (NAT) in $H$. $p y^{-}$ lori isolated from ulcer patients when treated with garlic compounds. The NAT enzyme 
was assayed using p-aminobenzoic acid (PABA) and 2-aminofluorene (2-AF) as substrates for acetylating reactions. Chung, (1999) [46], presented two assay systems: one with cellular cytosol and the other with intact cells as sources of enzymatic activity. The results indicated that NAT activity was decreased in those cases with $H$. pylori cytosols or cell suspensions were specifically treated with increased amounts of DAD or DADS. The data also indicated that both compounds decreased apparent $\mathrm{Km}$ and Vmax values of $H$. pylori NAT enzyme in both systems assayed. This was the first report that confirmed that garlic components can affect $H$. pylori growth and NAT activity.

Recently, Tang et al., (2014) [39] investigated the prevalence of $H$. pylori infection and its risk factors in Chengdu, China. The participants who ate raw garlic had a lower level of $H$. pylori infection than those who did not eat raw garlic $(52.6 \%$ vs. $67.9 \%, \mathrm{P}<$ 0.05 ), indicating that apparently raw garlic reduced the infection. A direct application of garlic extracts with no further purification can be accomplished for the treatment of $H$. pylori infection. In the future, this will require a development of new fields of research.

\section{Other Herbs and Species Extracts}

As a result of the use of diverse antibiotic treatments and better hygienic conditions, particularly in developed countries, this resulted in significant decline in the prevalence of $H$. pylori infection. However, persistent high $H$. pylori infection in developing countries, decreased patience compliance and emerging antibiotic resistance forced researchers to quest for novel candidates to fight $H$. pylori. Herbal medicines have always served as a leading source in drug discovery [47]. Since early times, herbs have been used to treat several disorders covering from minor inconveniences as pain up to life-threatening diseases like cancer. A number of studies from different parts of the world have shown promising properties of medicinal herbs not only against $H$. pylori but also associated disorders while employing in vitro, in vivo and clinical studies. Zaidi and collaborators [47] review these multiple pharmacological effects of medicinal plants and their chemical constituents in relation to $H$. pylori not only to evaluate the beneficial effects of these medicinal plants but to also critically analyze their putative roles as preventive agents' against $H$. pylori-associated disorders.

\subsection{Cinnamon Extracts}

Ethanol and methylene chloride (MC) extracts of cinnamon were studied to compare their in vitro effect on $H$. pylori growth and urease activity [48]. MC extract inhibited $H$. pylori growth at a concentration range of common antibiotics, while ethanol extract counteracted its urease activity. Complete inhibition was achieved by $50 \mu \mathrm{g} / \mathrm{ml}$ in solid media and $15 \mu \mathrm{g} / \mathrm{ml}$ in liquid media. Cinnamon extracts were more effective to inhibit free urease than urease bound to whole cells. Studies have been done to evaluate the effect of an ethanolic extract of cinnamon in a group of 15 patients infected with $\mathrm{H}$. pylo$r i$ [49]. Eight patients were given $40 \mathrm{mg}$ of ethanolic extract twice daily for 4 weeks and 7 received placebo. The amount of colonization was similar as estimated by the ${ }^{13} \mathrm{C}$ urea breath test before and after therapy. It was concluded that a daily dose of $80 \mathrm{mg}$ of cin- 
namon extract as the single agent was ineffective to eradicate $H$. pylori. A recent study [50] reported cinnamaldehyde (CM) as a major active constituent of cinnamon. Pre-incubation of cells (AGS/MKN-45) with CM significantly inhibited the IL-8 secretion/expression from $H$. pylori-infected cells $(\mathrm{p}<0.01)$. In addition, CM suppressed $H$. pylori-induced NF- $\kappa \mathrm{B}$ activation and prevented degradation of inhibitor (I)- $\kappa \mathrm{B}$. This study provides evidence that the anti-inflammatory effect of Cinnamomum cassia on H. pylori-infected gastric cells is due to blockage of the NF- $\kappa B$ pathway by cinnamaldehyde. This agent can be considered as a potential candidate for in vivo and clinical studies against $H$. pylori-related gastric pathogenic processes. Moreover, the combination of cinnamon extract with other antimicrobial agents at higher doses should be explored.

\subsection{Berry Extracts}

\section{Berry Extracts}

Chatterjee et al., (2004) [51] described the in vitro inhibitory effect of various berry extracts on the growth of $H$. pylori. Also, berry extracts produced enhanced susceptibility to clarithromycin. Bacterial suspensions were incubated for 18 hours with single extracts of raspberry, strawberry, cranberry, elderberry, blueberry and bilberry and with Optiberry ${ }^{\circledR}$, which is a mixture of these 6 types of berries, at $0.25 \%-1 \%$ concentrations. $H$. pylori growth was confirmed by CLO test (rapid urease test). All berry extracts significantly inhibited $(\mathrm{p}<0.05) H$. pylori growth, increasing susceptibility to clarithromycin $(15 \mu \mathrm{g} / \mathrm{ml})$, in particular, Optiberry, that showed maximal effects.

The combined use of silver nanoparticles (AgNps) and methanol extract of Solanum xanthocarpum, commonly known as yellow-berried nightshade effectively inhibited the growth of $H$. pylori, indicating a stronger anti- $H$. pylori activity than that of AgNO3 or metronidazole, being almost equally potent to tetracycline but less potent than amoxicillin and clarithromycin. Yellow-berried nightshade is a prickly plant, which grows wild in different regions of the Indo-Pakistan subcontinent has been tested and compare with typical antibiotics. AgNps (silver nanoparticles) sample and S1-extract with AgNps were found equally efficient when tested against the antibiotic-resistant or antibiotic-susceptible $H$. pylori strains. The anti- $H$. pylori activity was measured by the agar dilution method. The MIC90 was determined as standard procedure. The s1 extract contained typical Ag nanoparticles $(20 \mathrm{ml} 1 \mathrm{mM} \mathrm{AgNO} 3$ mixed with $10 \mathrm{ml}$ of $S$. xanthocarpum methanolic extract. Other $S$. xanthocarpum extracts were prepared to vary the amount of extract. In addition, after the $H$. pylori urease inhibitory assay, S1 exhibited a significant inhibition [52].

\subsection{Plant Extracts from Ancestral Traditional Medicine}

There are several studies done on different medicinal plants searching for anti- $H$. pylori activity described in differents countries and regions around the globe, such as Mali, Nigeria, South Africa (in Africa), Iran, Pakistan China Taiwan, Korea (in Asia), Southern Chios (Greek Island, Europe), Ecuador, Peru, Brazil, The Amazon (in South America). Table 1 shows a list of them. 
Table 1. Plant extracts from medicinal herbs and trees with anti- $H$. pylori activity.

\begin{tabular}{|c|c|c|c|c|}
\hline $\begin{array}{c}\text { Scientific name } \\
\text { or vernacular name }\end{array}$ & Type of extract ${ }^{a}$ & $\begin{array}{l}\text { MIC or } \mathrm{MIC}_{90} \\
(\mu \mathrm{g} / \mathrm{ml})^{\mathrm{b}}\end{array}$ & $\begin{array}{c}\text { Country of } \\
\text { origin }\end{array}$ & Reference \\
\hline Cominus ciminus & ET & 75 & & {$[53]$} \\
\hline Plrleopsis tuberosa & ME & $31.25-250$ & Mali (Africa) & {$[54]$} \\
\hline Allium ascalonicum & $\mathrm{E}$ & $6.25-12.5$ & & {$[55]$} \\
\hline Terminalia chebula Retz & AQ & $100-2500$ & $\begin{array}{l}\text { Iran } \\
\text { Iran }\end{array}$ & {$[56][57]$} \\
\hline Xantium. brasilicum & & $31.25-250$ & Iran & {$[56]$} \\
\hline Trachispermum copticum & & NA & Iran & {$[58]$} \\
\hline $\begin{array}{c}\text { Arbus cantoniensis, } \\
\text { Fabaceae }\end{array}$ & ET & 40 & China & {$[58]$} \\
\hline Saussu realappa, Asteraceae & & 40 & China & {$[58]$} \\
\hline $\begin{array}{c}\text { Eugeniacaryo } \\
\text { fillata, Myrtaceae }\end{array}$ & & 40 & China & [58] \\
\hline Plumbazo ceylanica & EA & $320-1280$ & Taiwan & [58] \\
\hline Germinaricum khatamsciz & & NA & Iran & {$[59]$} \\
\hline Terminalia macroptera & ET-ACE $(80-20)$ & 100 & Africa & {$[60]$} \\
\hline Terminalia catappa $\mathrm{L}$ & $\begin{array}{c}\text { AQ-ET, HEX, EA, } \\
\text { AQ }\end{array}$ & $125(\mathrm{AQ})$ & Brazil & {$[61]$} \\
\hline $\begin{array}{l}\text { Phyllanthus niruri L/ } \\
\text { Chancapiedra }\end{array}$ & $\mathrm{AQ}$ & NA & Ecuador-Peru & {$[62]$} \\
\hline $\begin{array}{c}\text { Calophylum brasiliense } \\
\text { Camb }\end{array}$ & & NA & Brazil & [63] \\
\hline Pistascia lenticus var chia & & NA & Brazil & {$[63]$} \\
\hline Eucalyptus torreliana & & 100 & & {$[64]$} \\
\hline Cambricum mella & & $1250-5000$ & & {$[65]$} \\
\hline Rhus verniciflua/Urishiol & & $64-256$ & Korea & [66] \\
\hline Acacianilotica & $\mathrm{ME} \& \mathrm{AQ}$ & $8-64$ & Pakistan & [67] \\
\hline Calotropis procera & ACE & NA & & {$[68]$} \\
\hline Geranium wilfordii & $\mathrm{ME} \rightarrow \mathrm{CHL} \rightarrow \mathrm{EA}^{\mathrm{c}}$ & $4-8(\mathrm{AQ})$ & $\begin{array}{c}\text { Brazil } \\
\text { (Amazon) }\end{array}$ & [69] \\
\hline Piper umbellatum & $\mathrm{AQ} / \mathrm{ET}$ & NA & Brazil (Amazon) & [69] \\
\hline
\end{tabular}

${ }^{\mathrm{a}} \mathrm{AQ}=$ aqueous, $\mathrm{ET}=$ ethanol, $\mathrm{ME}=$ methanol, $\mathrm{CHL}=$ chloroform, $\mathrm{ACE}=$ acetone, $\mathrm{HEX}=$ hexane, $\mathrm{EA}=$ ethylace-

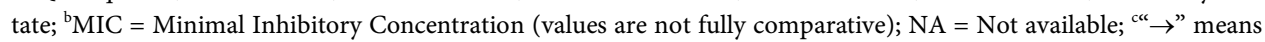
that these were sequential extractions.

In some cases extracts obtained with different organic solvent have been tested. In some others the chemical nature of the compound having this inhibitory has been identified. In few cases the target for these antimicrobials has been established. Some examples are cited below.

A group of 17 plants as ethanolic or aqueous extracts was studied as containing active agents for the treatment of $H$. pylori infections [53]. A standard laboratory $H$. pylori strain and 11 clinical isolates were tested by using disk diffusion test and MIC assay on solid medium. Inhibitory activity was detected in most of the tested plants. MIC values of ethanolic extracts were from 2 to 4 -fold lower concentrations than the aqueous ones. Particularly, ethanolic extracts of Cuminum cyminum and Propolis re- 
vealed MIC90 values of $75 \mu \mathrm{g} / \mathrm{ml}$, that represent significant in vitro effect of plant extracts that may contribute to the development of new and safe agents to control $H$. pylori infections.

At Mali, Western Africa, traditional medicine uses the plant Pteleopsis suberosa for the treatment of gastric and duodenal ulcers. Germano et al., (1998) [54] evaluated extracts of stem bark of this plant as anti-ulcer and antibacterial activity against a laboratory H. pylori strain and several clinical isolates. The decoction, the traditional form of administration of the drug in Mali and the methanolic extract were active against all strain tested. MIC ranged from 62.5 to $500 \mu \mathrm{g} / \mathrm{ml}$ of the decoction and 31.25 to 250 $\mu \mathrm{g} / \mathrm{ml}$ of the methanolic extract. These results suggest that this plant may be a source of the active compounds with therapeutic potential against diseases associated with $H$. pylori infections.

A methanolic extract from Allium ascalonicum Linn (Liliaceae) leaves has been tried in vitro on five strains of $H$. pylori by the agar diffusion method [55]. This plant contains alkaloids, cardiac glycosides, and saponins, as detected by phytochemical screening. The MIC of the extract against tested strains ranged from 6.25 to $12.5 \mu \mathrm{g} / \mathrm{ml}$. In addition, it was found that increasing concentrations of the extract decreased the urease activity of these strains. The results of this work suggest that Allium ascalonicum has some useful components to fight $H$. pylori infections.

Among several other plants studied, thyme, a low grower herb, with tiny white flowers lasting for several weeks each summer, was used as aqueous extract and resulted effective against $H$. pylori [70]. Since aqueous extract of thyme is easy to produce and consume, this preparation was further investigated. Compared to other antibacterial agents, thyme extract had significant inhibitory effects on $H$. pylori growth and urease activity. These findings wait for further validation through clinical studies.

A study of Wang et al., (1998) [71] described the effect of aloe-emodin on the NAT activity of $H$. pylori strains collected from patients with peptic ulcer. Assays using cytosols or suspensions of intact $H$. pylori cells showed that there was a decrease of bacterial NAT activity associated with an increase in aloe-emodin. Also, inhibition of $H$. pylori growth was aloe-emodin dose-dependent.

Another work was done by Malekzadeh et al., (2001) [57] found that water extracts of black myrobalan (Terminalia chebula Retz) had antimicrobial activity against $H$. $p y$ lori $(\mathrm{MIC}=125 \mu \mathrm{g} / \mathrm{ml}$ and $\mathrm{MBC}$ (Minimum Bactericidal Concentration $)=150 \mu \mathrm{g} / \mathrm{ml}$. This extract was active even after autoclaving for $30 \mathrm{~min}$ at $121^{\circ} \mathrm{C}$. In addition, this extract at the concentration of $1-2,5 \mathrm{mg} / \mathrm{ml}$ was able to inhibit urease activity of $H$. pylori, suggesting a possible therapeutic application.

Bae et al. (1998) [72] analyzed 5 plants as a source of antimicrobial activities against H. pylori: Coptidisjaponica (rhizoma), Eugenia caryophyllata (flower), Rheum palmatum (rhizoma), Magnolia officinalis (cortex) and Gallarhois Rusjavanica. All of them inhibited $H$. pylori growth but only Gallarhois extract showed inhibitory effect on $H$. pylori urease.

Grapefruit (Aristotochia pucinervis) methanolic and hexane extract fractions ob- 
tained from rhizome and leaves were effective as $H$. pylori growth inhibitors [73]. The A.pucinervis leaf hexane fraction (APLH) showed higher activity (MIC $=4 \mu \mathrm{g} / \mathrm{ml}$ ) than the rhizome hexane fraction (APRH, MIC $=16 \mu \mathrm{g} / \mathrm{ml}$ ). The leaf and rhizome methanol extracts were less active. This inhibitory activity was confirmed for active extracts and fractions against 20 clinical isolates by using determinations of their MIC50 and MIC90 values.

A study was done by Nariman et al., (2004) [56] testing 6 Iranian plants (Glycyrrhiza aspera, Juglans regia, Ligustrum vulgare, Thymus kotschyanus, Trachyspermum copticum, and Xanthium brasilicum) revealed that most active extracts to inhibit $H$. pylori growth were from $X$. brasilicum and T. copticum. (MIC range $=31.25-250 \mu \mathrm{g} / \mathrm{ml}$ ). Partial characterization identified a flavonoid and a xanthanolide.

Li et al., (2005) [58] studied extracts of 30 Chinese herbals frequently prescribed since ancient times for treating gastritis-like disorders. Among these, ethanol extracts of Abrus cantoniensis (Fabaceae), Saussu realappa (Asteraceae), and Eugenia caryofillata (Myrtaceae) were the most effective to inhibit the growth of $H$. pylori strains tested (MIC around $40 \mu \mathrm{g} / \mathrm{ml}$ ). Wang and Huang (2005) [74] assessed the anti- $H$. pylori activity of Plumbago zeylanica L. A previous work of this group carried out on 50 Taiwanese medicine.

Wang and Huang (2005) [74] assesed the anti-H. pylori activity of Plumbago zeylanica L. A previous work of this group carried out on 50 Taiwanese medicinal plants revealed that Plumbago zeylanica L had the highest antibacterial activity. Water and organic (ethanol, ethyl acetate, acetone) solvents were used to prepare the extracts. With the exception of the water extract, all the others showed high anti- $H$. pylori activity using agar diffusion and dilution methods. The ethyl acetate extract presented the lowest MIC $(0.32-1.28 \mathrm{mg} / \mathrm{ml})$ and bactericidal activity was obtained with concentrations ranged $5.12-20.48 \mathrm{mg} / \mathrm{ml}$. High $\mathrm{pH}$ stability was demonstrated for this extract in the range of $\mathrm{pH}$ 1-7 since its bactericidal activity was not affected.

Methanol extracts from roots of an endemic plant that grows in Iran (Geumiranicum Khatamsaz) which belongs to the Rosacea family have shown significant anti- $H$. pylori activity against a metronidazole resistant strain [59]. Using different chromatographic and spectroscopic methods, major compounds of this extract have been isolated and identified. The antimicrobial activity was established by the disk diffusion, microdilution and MIC methods tested on several Gram positive and negative bacteria. Nine compounds were identified: two triterpenoids, three sterols, one phenypropanoid (eugenol), one phenolic glycoside (gein), one flavonol (+), catechin and sucrose. The aqueous fraction after partitioning the methanolic extract with water and chloroform contained the highest activity and among the purified compounds eugenol was the most effective, however, the diglycosidic derivative was ineffective against $H$. pylori. MIC values indicated that Gram-positive bacteria were more susceptible than Gram-negative.

The root of Terminalia macroptera Guill \& Perr, (Combretaceae) has been widely used in African traditional medicine to treat different infectious diseases, including 
stomach-associated diseases. The study of Silva et al., (2012) [60] reported the in vitro activity of $T$. macroptera root extract against $H$. pylori clinical isolates. A T. macroptera root ethanol:water $(80: 20 \mathrm{v} / \mathrm{v})$ extract was analyzed against three reference strains and sixty-two $H$. pylori clinical isolates, revealing that $92 \%$ of the strains were sensitive to this extract. The supernatant of this fraction (Tmr-3) and the precipitate obtained from this fraction (Tmr-5) had the higher activities with an MIC50 of nearly $100 \mu \mathrm{g} / \mathrm{ml}$. The main compounds of Tmr and of Tmr-3 fractions were the ellagitannins called terchebulin and punicalagin.

Fractionated extracts of persimmon (Diospyros kaki) peels were studied for cytotoxic activity, multidrug resistance (MDR) reversal activity, anti-human immunodeficiency virus (HIV) activity and anti- $H$. pylori activity. The potent cytotoxic activity against human oral squamous cell carcinoma cells (HSC-2) and human submandibular gland tumor (HSG) cells was found in the acetone fractions (A4 and A5 fractions) with IC50 ranging from 21 to $59 \mu \mathrm{g} / \mathrm{ml}$. However, the cytotoxic activity was not correlated with the radical intensity of the fractions. Three $70 \% \mathrm{MeOH}$ extract fractions (70M2-4) produced radical and efficiently scavenged the $\mathrm{O}_{2}^{2-}$ produced by hypoxanthine and xanthine oxidase reaction. All of the fractions tested were not effective as anti- $H$. pylori and anti-HIV agents. Fractions $\mathrm{H} 3$ and $\mathrm{H} 4$ of hexane extract, and M2 and M3 of $\mathrm{MeOH}$ extract showed a remarkable MDR reversal activity comparable with that of $(+/-)$-verapamil (a positive control). These results indicate the therapeutic value of persimmon peel extracts as potential antitumor and MDR-reversing agents.

Ranilla et al (2012) [62] have studied water extracts from an Amazon medicinal plant called "Chancapiedra" (Phyllanthus niruri L.) from Ecuador and Peru. These extracts displayed proficient antimicrobial activity against $H$. pylori whereas different strains of lactic acid bacteria such as Lactobacillus acidophilus, Lactobacillus casei and Lactobacillus plantarum were not inhibited. $H$. pylori were inhibited by water extracts collected from plants of both countries in a dose-dependent manner. Both extracts contained ellagic acid and hydroxycinnamic acid derivatives and displayed high free radical scavenging linked-antioxidant activities. However, gallic acid was detected only in the Ecuadorian extract. Regarding the Chancapiedra mechanism of action against $H$. pylori it has been proposed that inhibition may not involve inhibition of oxidative phosphorylation by proline dehydrogenase associated with simple mono-phenolics but rather involve ellagitannins or other non-phenolic compounds through a yet unknown mechanism. The advantage of Chancapiedra as an inhibitor of $H$. pylori growth is that this extract does not affect beneficial lactic acid bacteria.

Guanandi (Calophyllum brasiliense Camb), is a large tree belonging to Clusiaceae family widely distributed in Latin America that grows in tropical and swampy areas in Brazil. From its stem bark produces an exudate similar to latex, which has been used in folk medicine for treatment of gastric ulcer among other disease and symptoms [75] [76]. Several compounds have been obtained from its stem bark, such as chromanone acids. In order to evaluate its anti-ulcer activity and probable mechanism(s) of action, a fraction with a mixture of chromanone acids (BI), collected after purification by col- 
umn chromatography of a stem bark hexane extract of Calophyllum brasiliense (HECb) has been tested, using experimental in vitro and in vivo models [63]. The ulcer was induced in mice by oral administration of ethanol (75\%, v/v) and indomethacin (50 $\mathrm{mg} / \mathrm{kg}$ ). For evaluation of a hexane fraction of an extract of the stem bark of Calophyllum brasiliense containing a mixture of chromanone acids (BI) on nitric oxide (NO) level, the ulcer was induced by ethanol in N-Nitro L-Arginine Methyl Ester (L-NAME) pretreated animals. Anti- $H$. pylori activity was tested in disk diffusion and broth microdilution in vitro assays, usingcagA + and vacA $+H$. pylori strains. BI fractions avoided gastric ulceration caused by ethanol and indomethacin treatments. The gastroprotective mechanism of $\mathrm{BI}$ in ethanol-induced ulcer was partly due to reduction of Malondialdehyde (MDA) and Catalase (CAT) levels in the gastric tissue. BI did not affect glutathione (GSH) levels and its gastroprotective effect was not reversed by pretreatment with L-NAME. BI showed anti- $H$. pylori activity in both assays. The results indicated that $\mathrm{BI}$ is partly responsible for the anti-ulcer and anti- $H$. pylori effects of HECb.

A resin known as mastic, was obtained from Pistacia lentiscus (L.) var. chia (Duham), an evergreen shrub belonging to the family Anacardiaceae and uniquely cultivated in Southern Chios, a Greek island [77]. It has been used for more than 2500 years in traditional Greek medicine to treat gastralgia and peptic ulcers, while the effects of the gum have been mentioned by Herodotus and Galen. Several Roman, Byzantine, Arab and European authors have mentioned mastic's healing properties. Modern science has justified the beneficial action of mastic on gastric diseases, by its inhibitory action either in vivo or in vitro, against $H$. pylori. In addition, there are studies on its antimicrobial, antifungal, antioxidant, hypolipidemic and anti-inflammatory properties, as well as anti-Crohn disease and anticancer activities.

In Nigeria, Eucalyptus torelliana F. Muell leaf extracts have been used in traditional medicine to treat Peptic Ulcer Disease (PUD) and other gastrointestinal disorders. These extracts present additive and synergistic effects when given in combination with clarithromycin, Studies done by Lawal et al., (2012) [64] on $2 \mathrm{H}$. pylori strains (ATCC 43629 and ATCC 43579) and 4 clinical isolates using a checkerboard assay established the fractional inhibitory concentration (FIC) index [64]. A time-kill study was also accomplished using $H$. pylori ATCC 43579. It was found that E.torelliana extract inhibited $H$. pylori growth in all tested cases, and the addition of one identified active compounds (a substituted pyrenyl ester) enhanced the activity of clarithromycin. When mixed, the MIC values of each one were reduced twofold, from 0.125 to $0.0625 \mu \mathrm{g} / \mathrm{ml}$ in clarithromycin and from $>100$ to $50 \mu \mathrm{g} / \mathrm{ml}$ the pyrenyl ester. After 3 hours of exposure to a combination of $0.25 \mu \mathrm{g} / \mathrm{ml}$ clarithromycin and $100 \mu \mathrm{g} / \mathrm{ml}$ of the pyrenyl ester reduced $100 \%$ growth of $H$. pylori ATCC 43579. This demonstrates that sometimes combination of plant compounds and antibiotics may be quite effective for treatment of $H$. pylori infections.

Ferreira et al., (2012) [78] reported in vitro antimicrobial studies with different crude extracts obtained from 2 plants: Cistus ladanifer, a flowering plant in the Cistaceae fam- 
ily and Arbutus unedo (strawberry tree), a tree with edible fruits. Both species are native from Western Mediterranean region. Extracts were prepared in a different way. The antimicrobial activities were tested on reference strains, including three Gram-positive, five Gram-negative and three yeasts, and on several clinical isolates of $H$. pylori and methicillin-resistant Staphylococcus aureus strains. All extracts presented in vitro activity against the Gram-positive bacteria, Klebsiella pneumoniae, Candida tropicalis and $H$. pylori, being particularly effective on the last one.

Njume et al., (2011) [65] have studied the susceptibility of 32 clinical strains of $H$. pylori and a reference strain against 5 solvent extracts of Combretum molle, a plant widely used for the treatment of gastric ulcers and other stomach-related morbidities in South Africa. The extracts were screened for activity by the agar-well diffusion method, and the most active were tested against the same strains by micro-broth dilution and time-kill assays. Metronidazole and amoxicillin were included as positive controls. All extracts showed anti- $H$. pylori activity with halo diameters of inhibition between 0 and $38 \mathrm{~mm}$. The most active extract against $H$. pylori was the acetone extract, to which $87.5 \%$ of the clinical isolates were susceptible. The MIC90 values for this extract ranged from 1.25 to $5.0 \mathrm{mg} / \mathrm{ml}$ while those for amoxicillin and metronidazole ranged from 0.001 to $0.94 \mathrm{mg} / \mathrm{ml}$ and from 0.004 to $5.0 \mathrm{mg} / \mathrm{ml}$ respectively. The acetone extract was highly bactericidal at a range of $2.5-5.0 \mathrm{mg} / \mathrm{ml}$, with the total elimination of the bacteria in 24 hours. Its inhibitory activity was better than that of metronidazole $(\mathrm{p}<0.05)$.

Another example of plant product with antimicrobial activity against $H$. pylori is Urushiol [66]. This is one of the main components of the lacquer tree, which has been used as a folk remedy for the relief of abdominal pain in Korea. Monomers and tetramers of polymeric urushiol were used. In the in vitro study, $\mathrm{pH}$ - and concentration-dependent antibacterial activity of the urushiol against $H$. pylori was investigated. In addition, the serial morphological effects of urushiol on $H$. pylori were examined by electron microscopy. Ananimal study was performed to assess the safety, eradication rate, and the effect of urushiol on gastritis. The MIC of the extract against strains ranged $0.064-0.256 \mathrm{mg} / \mathrm{ml}$. Urushiol caused separation of the membrane and lysis of H. pylori within 10 minutes. Urushiol $(0.128 \mathrm{mg} / \mathrm{ml}$ given by 7 days did not cause complications on mice. The eradication rates were $33 \%$ in the urushiol monotherapy, $75 \%$ in the common triple therapy (omeprazole + clarithromycin + metronidazole), and $100 \%$ in the urushiol + triple therapy, respectively. $H$. pylori-induced gastritis was not changed by urushiol but reduced by eradication. Expression of interleukin- $1 \beta$ in the gastric tissue was significantly increased by $H$. pylori infection and reduced by the urushiol and $H$. pylori eradication $(\mathrm{p}=0.014)$. The urushiol has an antibacterial effect against $H$. pylori infection and may be used for $H$. pylori eradication.

There are a number of plants in Pakistan such as Acacia nilotica (L.), Delile, Calotropis procera (Aiton), T.T (Aiton), Adhato davasica Nees, Fagonia arabica and Casuarina equisetifolia L, which have been traditionally used in folk medicine. A recent study carried out by Amin et al., (2013) [67] tested the presence of anti-H. pylori activity and urease inhibition by different extracts of these plants, native from Soon Valley, Punjab, 
on 34 clinical isolates and 2 reference strains. Methanol and acetone extracts from Acacia nilotica and Calotropis procera showed stronger anti- $H$. pylori activity than metronidazole but were less efficient than amoxicillin and clarithromycin. Both extracts also showed significant inhibition of urease activity. Other extracts displayed lower activity that other used antibiotics. A competitive inhibition mechanism for urease by Acacianilotica extract was suggested.

Another plant, Geranium wilfordii Maxim, widely used in Chinese Herbal Medicine to treat gastrointestinal disorders has been studied by Zhang et al., (2013) [68]. An ethanol extract was further fractionated by chloroform, ethyl acetate, and n-butyl alcohol extractions. Using a reference strain and 5 clinical isolates strong inhibition of $H$. pylori growth was detected in the ethanol and ethyl acetate fraction and corilagin and 1 , 2, 3, 6 tetra-O-galloyl- $\beta$-D-glucose were identified. These compounds displayed MIC values of 4 and $8 \mathrm{mg} / \mathrm{ml}$ respectively.

A recent study has been done to evaluate the anti- $H$. pylori activity of Alchemilla glabra Neygenf (Alchemilla), A. monticola Opiz (Plicatae S.E. Fröhner), A. fissa Günther and Schummel (Calycinae Buser) and A. viridiflora Rothm (Calycinae), and identified ellagic acid and quercetin-3-O- $\beta$-glucoside. Anti- $H$. pylori activity was tested against ten clinical isolates and one reference strain (ATCC 43504). The methanol extracts were more active than the dichloromethane and cyclohexane extracts. The ranges of concentrations were between $4 \mu \mathrm{g} / \mathrm{ml}$ for methanol extracts of $A$. viridiflora, $A$. glabra and $A$. monticola, and $256 \mu \mathrm{g} / \mathrm{ml}$ for cyclohexane extracts of $A$. viridiflora, $A$. glabra and $A$. fissa. The best inhibitory activity was obtained with $A$. monticola extracts. No significant difference was found in the ellagic acid contents of the methanol extracts of the Alchemilla species $(0.2-0.3 \mathrm{mg} / \mathrm{ml})$, and anti- $H$. pylori activity was similar (4 $32 \mu \mathrm{g} / \mathrm{ml})$. Ellagic acid exhibited strong activity at very low concentrations (0.125-0.5 $\mu \mathrm{g} / \mathrm{ml}$ ), while the second identified compound, quercetin-3-O- $\beta$-D-glucoside, was also very active but at the concentration of $2-16 \mu \mathrm{g} / \mathrm{ml}[79]$.

A recent study [69], on Piper umbellatum L. (Piperaceae), a shrub found in the Amazon, Savannah and Atlantic Forest region of Brazil was carried out. Extracts of this plant are frequently used in folk medicine in many countries primarily for the treatment of gastric disorders. These authors evaluated the gastroprotective and anti-ulcer effects of an hydro-ethanolic extract of $P$. umbellatum (HEPu) leaves in experimental rodents. HEPu extract demonstrated potent gastroprotection against acute ulcer induced by acidified ethanol and excellent healing effect of the chronic ulcer induced by acetic acid. The gastroprotective activity in acidified ethanol is partly attributed to the antioxidant mechanisms, while anti-secretory, anti-inflammatory and regeneration of the gastric mucosa are evoked as part of its antiulcer mechanism of action. The gastric ulcer healing of HEPu involves restoration of the altered cytokines levels to near normal. It has no in vitro anti- $H$. pylori activity. These results showed that HEPu possesses preventive and curative effects in experimental models of gastric ulcers in animals. These effects are partially dependent on antioxidant, anti-secretory, anti-inflammatory and mucosa regeneration. It is independent of anti- $H$. pylori activity, with substances 
probably responsible for the pharmacological activity being flavonoids, quercetin, and rutin. These results support the popular use of $P$. umbellatum leaves in the treatment of peptic ulcers. The combined use of different extracts could be useful to counteract different symptoms of $H$. pylori infection.

\subsection{Pomegranate Extracts}

Pomegranate tree (Pome granatum) is originally from Occidental Asia and Mediterranean Europe with an extent history of use in traditional medicine. Leaves, flowers, fruits and seeds of this plant have been used to ameliorate diseases. There are several reports indicating that various extracts and their purified fractions have antibacterial activity against Gram positive and Gram negative [80] [81] [82] including methicillin-resistant Staphylococcus aureus [83] [84], multidrug-resistant Salmonella typhi [85] and against food-borne pathogens and spoilage bacteria displaying antidiarrheal and tanicidal activities. Also, a recent review reported anti-inflammatory, antioxidant and anticancer effects [86].

The only human trials examining the antibacterial properties of pomegranate extracts have focused on oral bacteria [87] [88] [89] [90]. However, several in vitro assays demonstrated its bactericidal activity against several highly pathogenic and sometimes antibiotic-resistant microorganisms. Brazilian researchers evaluated the synergistic effect of a $P$. granatum methanolic extract with five antibiotics on 30 clinical isolates of methicillin-resistant Staphylococcus aureus (MRSA) and methicillin-sensitive $S$. aureus [84]. The antibiotics tested were chloramphenicol, gentamicin, ampicillin, tetracycline, and oxacillin. Although synergistic activity between the pomegranate extract and all five antibiotics was noted in the $S$. aureus isolates, synergy with ampicillin was most pronounced. A combination of the two increased the lag time to bacterial growth by three hours (over that ampicillin alone) and was also bactericidal as evidenced by a 72.5-percent reduction in methicillin-sensitive organisms and a 99.9-percent reduction in MRSA. Based on earlier research [91] and the results of the above studies, ellagitannin and punicalagin are thought to be the primary constituents responsible for the observed antibacterial effects. Ellagitannins, ellagic acid, and punicalagin have been described as its antimicrobial bioactive compounds among others [86].

During recent years, a problem due to antibiotic resistance by bacteria has emerged and requires the search for novel compounds to be used as therapy agents. Recently, Hajimahmoodi et al., (2011) [92] evaluated in vitro anti- $H$. pylori activity of selected medicinal plants on clinical isolates of $H$. pylori obtained from patient biopsies. These authors assayed in triplicate 23 methanol extracts from Iranian plants. Among these, extracts from Punica granatum (Pomegranate) and Junglans regia (Persian walnut) presented the higher anti- $H$. pylori activities. The group of Hajimahmoodi used the disc-diffusion method to establish the susceptibility of three $H$. pylori isolates to methanol extracts of these Iranian plants, with a mean of inhibition zone diameters of 39 and $16 \mathrm{~mm}$ respectively when using $100 \mathrm{mg}$ of each per disc.

Based on these results, peel extracts from nine different cultivars of Punica granatum 
were further tested. It was found that all but excepting one pomegranate cultivar had significant high in vitro activity against $H$. pylori with inhibition zone diameter mean ranged from 16 to $40 \mathrm{~mm}$ at $50 \mathrm{mg}$ per disc.

One of the most recent reports regarding pomegranate extracts was published by Haghayeghi et al., (2013) [93]. This group determined the antimicrobial activity of pomegranate juice against 40 food-borne pathogens, representing 8 bacterial species, including $H$. pylori. No synergism in antimicrobial activity was observed among pomegranate juice and either barberry, oregano or cranberry. The antimicrobial activity of the pomegranate juice varied depending on the tested microorganisms and the method of extraction. The high sensitivity of $H$. pylori strains to the pomegranate juice suggests that this juice may be an alternative or supplemental treatment to control gastric ulcers caused by this organism.

\section{Purified Compounds (Phytodrugs)}

\subsection{Vitamins and Antioxidants}

$\mathrm{N}$-acetyltransferase enzyme (NAT) is a ubiquitous enzyme found in bacteria, fungi and protozoa, mammals and even common fruits and vegetables. This NAT activity has been demonstrated to be present in some human gastrointestinal flora [94]. Since $H$. pylori have been associated with gastric cancer it would be to evaluate the effect of some vitamins on the NAT activity detected in this bacterium.

In this context, the effect of vitamin $\mathrm{E}$ on the arylamine $\mathrm{N}$-acetyltransferase activity in $H$. pylori strains isolated from patients with peptic ulcers has been studied. Chung (1999) [46] described that treatment of $H$. pylori with different concentrations of vitamin $\mathrm{E}$ showed different percentages of 2-AF (2-amino fluorene) acetylation indicating that an increased NAT activity associated with increased levels of vitamin $\mathrm{E}$ in $H$. pylori cytosol as well as intact bacteria. It was found that apparent values of $\mathrm{Km}$ and Vmax of NAT enzyme were increased when vitamin $\mathrm{E}$ was added to the mixtures of 2-AF and PABA acetylation, respectively. This was the first report that antioxidants such as vitamin E can promote $H$. pylori NAT activity. In addition, a study of Chuang et al., (2002) [95] described that vitamins $\mathrm{C}$ and $\mathrm{E}$ as supplements to normal triple therapy may reduce eradication rate of metronidazole-susceptible $H$. pylori as well as gastric inflammation in infected patients. A group of infected patients treated with lansoprazole, amoxicillin, metronidazole and vitamin E (200 $\mathrm{mg})$ and vitamin C (200 mg) twice daily for one week following by only vitamins (same doses) once daily for 6 consecutive weeks revealed that $H$. pylori eradication tested 8 weeks post-treatment was not different compared to the treatment without vitamins. In conclusion, adding vitamin $\mathrm{C}$ and E to the triple therapy do not improve $H$. pylori eradication rate and gastric inflammation.

Another study reported by Chatterjee et al., (2003) [96] described the effect of two anti-oxidants on the growth of H. pylori: Garcinol and Protokin, a commercial compound (InterHealth Nutraceuticals, CA, USA) containing 50\% of resveratrol. Garcinol resulted in a bactericidal agent more effective than resveratrol when tested in vitro on 
H. pylori ATCC 49503.

\subsection{Phytochemicals as Antioxidants}

Several compounds present in food extracts have been used to reduce the risk of damage due to $H$. pylori infections. Epigallocatechin-3-gallate present in green tea inhibited the urease enzyme of these bacteria in vitro and also in vivo, after infection of Mongolian gerbils [97]. Sulforaphane (SFN), which is present in large amounts in broccoli sprouts presented an anti-bacterial activity on $H$. pylori through a still unknown mechanism, producing a chemoprotective effect and reducing bacterial colonization in $H$. pylori infected mice and also humans [98] [99]. Since the list of these compounds is extent, we will revise few of these cases only (Table 2). A recent review [100] analyzed the documented evidence of studies about broccoli, glucoraphanin (Gra) and Sulforaphane (SFN) on human subjects. The review covered seventeen studies, and the predominant intervention used broccoli sprouts. Comparative values of clinical parameters such as blood glucose and lipid profile and molecular parameters of oxidative stress indicated an improvement after intervention. Less solid evidence was concluded with respect to reduced inflammation, Helicobacter pylori colonization, and protection against cancer. Although the results seem relevant, the evidence for the use of broccoli, GRA, and SFN in humans is limited. Additional intervention studies will be needed to evaluate outcomes more consistently with solid conclusions.

\subsection{Flavonoids and Polyphenols}

The inhibitory effect of flavonoids and phenolic acids, which could be transformed from flavonoids by human intestinal microflora, on $H$. pylori growth has been studied [101]. Ponciretin, hesperetin, naringenin and diosmetin were active against this bacterium. Among them, ponciretin was the strongest growth inhibitor $(\mathrm{MIC}=10-20$ $\mu \mathrm{g} / \mathrm{ml}$ ). In contrast, these compounds did hardly inhibit the urease activity of $H$. pylori.

Other flavonoids have been obtained from the licorice (Glycyrrhiza uralensis) root extract [102]. Licorice is a commonly used crude drug in Kampo medicine (traditional Chinese medicines modified in Japan). Initially, the extract of this type of plants has been the basis of anti-ulcer medicines. Among the constituents of these plants, glabridin and glabrene (Glycyrrhizaglabra), licochalcone A ( . inflata), licoricidin and licoisoflavone B ( $G$. uralensis) showed inhibitory activities against the growth of $H$. pyloriin vitro. These flavonoids were also active on clarithromycin and amoxicillin resistant strains. From a methanol extract of G. uralensis, Fukai et al., (2002) [102] isolated 3 new isoflavonoids (3-aryl coumarin, pterocarpan, and isoflavan) with a pyran ring among several other known flavonoids. Among these compounds, vestitol, licoricone, 1-methoxy-phaseollidin and gancaonol $\mathrm{C}$ showed antimicrobial activity against clarithromycin and amoxicillin resistant- as well as against sensitive $H$. pylori strains.

A recent work of Isobe et al., (2006) [105] identified the presence of 2 flavonoids very effective against $H$. pylori in a Brazilian medicinal plant called Hyptis fasciculata. The plant is used as an expectorant, sudorific and to treat spasm sputum. These authors 
Table 2. Characteristics of purified and identified compounds from plants and oils with activity anti- $H$. pylori.

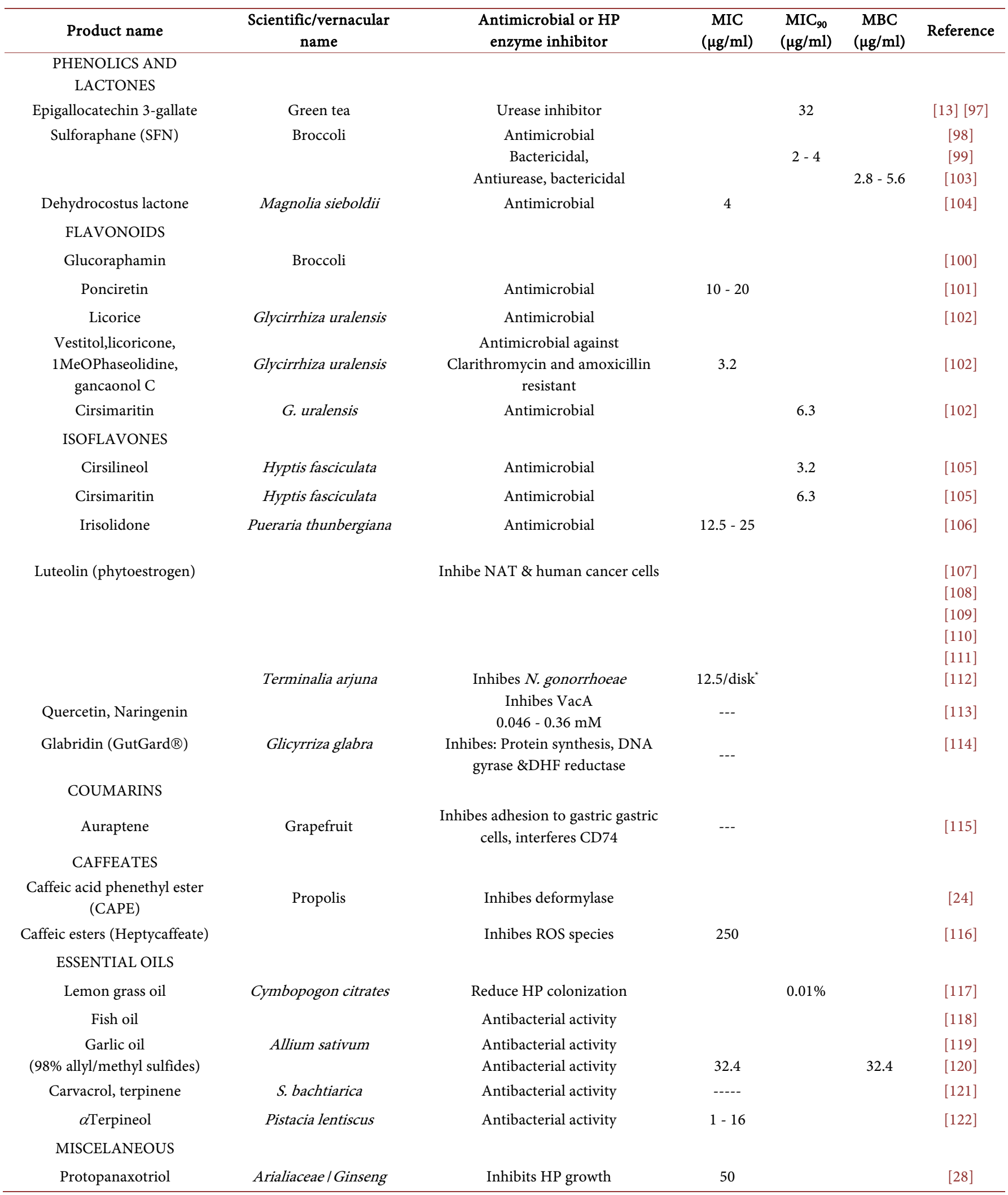

Table footnote: If $H$. pylori MIC values are not displayed it means that were not available. 
characterized the active constituents which resulted in the isolation of 5 known compounds: cirsilineol, cirsimaritin, aurantiamide acetate, aurantiamide benzoate and methoxy-nepetaefolin and 2 new diterpenoids. The extraction of the mashed aerial part of the plant was done with chloroform and then methanol. The chloroform extract was separated with an MPLC (Medium Pressure Liquid Chromatography) system and eluted with different solvents. The methanol extract was partitioned in water and ethyl acetate. The ethyl acetate fraction was further separated in a solvent system. The water soluble fraction was separated by MLPC method. The characterization was mainly done by NMR and mass spectrometry. These authors found that cirsilineol exhibited potent anti- $H$. pylori activity (IC90 $=3.2 \mu \mathrm{g} / \mathrm{ml})$ but weak activity against Escherichia coli and Salmonella enteritidis. Cirsimaritin was also active against $H$. pylori $(6.3 \mu \mathrm{g} / \mathrm{ml})$ but having activity on other microorganisms as well. Considering structural features of these compounds they propose that flavonoids with potent activities had mainly adjacent dimethoxy-groups, especially at positions 6 and 7, and simultaneously some hydroxyl groups in the molecule as cirsilineol and cirsimaritin. The targets for these compounds have not been yet identified.

Isoflavones isolated from the flowers and rhizomes of Pueraria thunbergiana (Leguminosae) were tested on the growth of $H$. pylori [28]. It was found that isoflavones glycosides did not affect the bacterial growth. In contrast, their aglycones, irisolidone, tectorigenin and genistein did so. Among them, irisolidone had the highest growth inhibitory activity against $H$. pylori $(\mathrm{MIC}=12.5-25 \mu \mathrm{g} / \mathrm{ml}$. Genistein only weakly inhibited urease from $H$. pylori and a $\mathrm{H}+/ \mathrm{K}(+)$-ATPase of rat stomach $($ IC50 $=0.43$ and $0.89 \mathrm{mg} / \mathrm{ml}$ respectively).

Another studied flavonoid is luteolin

(2-[3,4dihydroxy-phenyl]-5,7-dihydroxy-4H-1-benzopyran-4one) defined as a type of phytoestrogen which is present in many plants (family Combretaceae). In particular, the red bell pepper has been demonstrated to contain an abundance of luteolin [106] [107]. Chung et al., (2001) [108] demonstrated that this compound inhibited uncompetitively the $H$. pylori NAT enzyme previously mentioned. Luteolin has been previously reported to be able to inhibit the growth of different kinds of human cancer cell lines (lung, ovary, melanoma, gastric) [109] [110] [111] and also exhibit antimutagenic activity in the bay region of diol epoxides of polycyclic aromatic hydrocarbons [123]. In addition, it has been shown that inhibit the growth of Neisseria gonorrhoeae with a $\mathrm{MIC}=12.5 \mu \mathrm{g} / \mathrm{disk}[112]$.

Since in most cases the target for antimicrobial activity of flavonoids and polyphenols has not been described, recent works of Shin (2005) [124] and Yahiro et al., (2005) [113] are quite interesting because they demonstrated that these compounds affect the activity of an $H$. pylori vacuolating toxin (VacA), one of the major virulence factors of H. pylori. Flavonoids quercetin and naringenin inhibited vacuolation of HeLa cells caused by VacA with IC50 values of 0.046 and $0.36 \mathrm{mM}$ respectively. In addition, quercetin also inhibited procaspase- 3 activation to caspase- 3 in HeLa cells induced by VacA cytotoxin. This toxin may induce cell death by proteolytic activation of a cascade of 
caspases. In any case, quercetin does not affect Bax andBcl-2 protein levels. Shin et al., concluded that quercetin may improve gastric cell death by inhibition of apoptotic signaling caused by VacA. The work of Yahiro et al., (2005) [113] focused on the effect of polyphenols on VacA. The authors analyzed VacA uptake and VacA-induced RPTPa and RPTP- $\beta$ VacA binding to RPTP receptors and vacuolation in susceptible cells. Hop bract extract (HBT) inhibited VacA in a concentration-dependent manner, binding to VacA receptors, RPTP $\alpha$ and RPTP $\beta$, which are in charge of VacA uptake and VacA-induced vacuolation in susceptible cells. The effect of HBT with high MW polymerized catechin on VacA was tested by quantifying gastric damage after oral administration of the cytotoxin to mice. HBT showed the strongest inhibitory activity on VacA among polyphenols studied, inhibiting the binding of VacA to the receptors, VacA uptake, and vacuolation. In addition, oral administration of HBT with VacA to mice reduced VacA-induced gastric damage at 48 hours. HBT formed a complex (in vitro) with VacA and may be a useful new type of therapeutic agent for the prevention of gastric ulcer and inflammation caused by VacA.

Traditional medicine in India has employed Glycyrrhiza glabra Linn, a plant belonging to a legume family (Fabaceae) that grow as small bushes in Asia, Australia, Europe and the Americas, in the treatment of peptic ulcer caused by H. pylori. Recently, Asha et al., (2013) [114] have done studies to evaluate the anti- H. pylori action of GutGard ${ }^{\circledR}$, a flavonoid-rich extract from Glycyrrhiza glabra in order to elucidate the possible mechanisms of its anti-H. pylori activity. By using Agar dilution and micro broth dilution methods, the MIC of GutGard ${ }^{\circledR}$ against $H$. pylori was obtained. Glabridin, the main flavonoid present in GutGard ${ }^{\circledR}$ presented a remarkable activity against $H$. pylori while glycyrrhizin did not show this activity even at $250 \mu \mathrm{g} / \mathrm{ml}$ concentration. In a protein synthesis assay, GutGard ${ }^{\circledR}$ caused a significant time-dependent inhibition of protein synthesis as measured by ${ }^{35} \mathrm{~S}$-methionine incorporation into H. pylori ATCC 700392 strain. Additionally, GutGard ${ }^{\circledR}$ showed a strong inhibitory effect on DNA gyrase and dihydrofolate reductase with IC50 values of $4.40 \mu \mathrm{g} / \mathrm{ml}$ and $3.33 \mu \mathrm{g} / \mathrm{ml}$ respectively. However, the extract did not show significant inhibition on the adhesion of $H$. pylori to human gastric mucosal cell line. These assays revealed that GutGard ${ }^{\circledR}$ acts against $H$. pylori possibly by causing inhibition of protein synthesis, DNA gyrase and dihydrofolate reductase.

\subsection{Coumarins}

Recently, Sekiguchi et al., (2012) [115] have reported that auraptene, a compound present in citrus fruit such as grapefruit (Citrus paradici) and hassaku (Citrus hassaku) inhibit adhesion of $H$. pylori to gastric cells by interference with expression of CD74, which has been identified as a receptor which binds $H$. pylori urease [125]. After oral administration of auraptene to mice infected with $H$. pylori, colonization and gastritis as result of inflammatory responses in C57BL/6 mice were remarkably attenuated. Biochemical analyses revealed that auraptene inhibited $H$. pylori-induced expression and/or production of CD74, macrophage migration inhibitory factor, IL- $1 \beta$, and TNF- $\alpha$ 
in gastric mucosa, together with serum MIP-2 (macrophage inhibitory protein-2). Treatment with this coumarin during the pretreatment period was more effective than post-treatment. These results suggest that auraptene is able to reduce gastritis and carcinogenesis associated with $H$. pylori.

\subsection{Caffeates}

A recent study of Paracatu et al., (2014) [116] was focused on caffeic acid and their esters and the inhibition of reactive oxygen species (ROS) usually released by neutrophils activated by $H$. pylori and the bactericidal activity of these compounds. Ester derivatives have higher hydrophobicity which improved their efficiency as bactericidal compounds when tested on $H$. pylori and as inhibitors of ROS production. For instance, the MIC values for bactericidal activity decreased from $1000 \mu \mathrm{g} / \mathrm{ml}$ for caffeic acid to 250 $\mu \mathrm{g} / \mathrm{ml}$ for butyl and heptylcaffeates. Also, caffeates caused higher inhibition of ROS, superoxide anion and hypochlorous acid release by activated neutrophils.

Njume et al. (2011) [65] studied the activity of both acetone and aqueous plant extracts and theysuggested that Sclerocarya birrea, a medicinal plant, contains at least two different anti- $H$. pylori components, reiterating the potential of this plant as a possible source of antimicrobial agents against $H$. pylori. The acetone crude extract generally exhibited a better antimicrobial potential than the aqueous extract. This can be attributed to the presence of many more active components in this extract as revealed in the TLC analysis.

\section{Essential Oils}

Essential oils, which are extracted from plants (e.g., leaves, peels), showed the growth inhibition of $H$. pylori in vitro [126] [127] and in vivo studies on mice [117]. Among 13 essential oils utilized in an in vitro study, lemongrass oil was utilized on in vivo study because of the lowest in vitro MIC value described. The density of $H$. pylori colonization in the mice stomach treated with lemongrass oil was significantly reduced compared with untreated mice [117].

Considerable work on naturally occurring $H$. pylori therapeutics has focused upon the truly lipoidal oils, which include short-, medium-, and long-chain fatty acids as well as monoglycerides; and polyunsaturated fatty acids (commonly referred as PUFAs). Fish oil [118], garlic oil [119], and blackcurrant seed oil (rich in $\omega$-3 and $\omega$ - 6 unsaturated fatty acids) [128] [129] all have in vitro antibiotic activity against $H$. pylori. Fish oil showed activity against $H$. pylori in humans [130]. Evening Primrose oil (rich in $\omega-6$ unsaturated linoleic acid) healed ulcers in rats [131] and consumption of fish oil is inversely associated with the prevalence of duodenal ulcer. Garlic oil has been assayed in a simulated gastric environment showing MIC and MBC values of $32.4 \mu \mathrm{g} / \mathrm{ml}$ [120].

Numerous investigators have reported in vitro positive effects of specific polyunsaturated fatty acids against H. pylori [132] [133] [134], but studies in humans have been controversial, with some studies showing anti- $H$. pylori activity and others showing none [135]. Anti-inflammatory activity has been reported [136], as a protective feature 
against ulcer formation [137], a reduced risk for development of atrophic gastritis [137], and suppression of gastric acid secretion [8]. Shorter chain fatty acid with activity against $H$. pylori has only been demonstrated in vitro [137].

Satureja bachtiarica Bunge is traditionally used as the antimicrobial agent. In a recent study, Falsafi et al., (2015) [121] evaluated the antibacterial activity of $S$. bachtiarica Bunge essential oil against 10 clinical isolates of $H$. pylori by disc diffusion and agar dilution methods. The chemical composition of this essential oil was revealed by GC (Gas Chromatography) and GC-MS (Gas Chromatography-Mass Spectrometry). Carvacrol (45.5\%) and thymol (27.9\%) were the primary constituents of oil, followed by p-cymene (4.4\%), and $\gamma$-terpinene (4.0\%). S. bachtiarica essential oil showed strong antibacterial activity against clinical isolates of $H$. pylori $(17.6 \pm 1.1 \mathrm{~mm}$ and $0.035 \pm 0.13$ $\mu \mathrm{l} / \mathrm{ml}$ ). Carvacrol, as the first main component, had a significant role in this effect, whereas, in the presence of thymol, the antibacterial effect of carvacrol was reduced. Therefore, $S$. bachtiarica essential oil can be applied as an alternative agent for treatment of $H$. pylori infections. More studies would be required to better clarify its mechanism of action on $H$. pylori.

\section{Probiotics to Treat $H$. pylori Infections}

\section{Probiotics in the Treatment of $h$. Pylori Infections}

Probiotics, according to Fueller (1989) [138] are defined as "microorganism belonging to the intestinal microbiota, present in the gastrointestinal system of animals including humans that has a beneficial effect in the host by improving the intestinal balance." Probiotics are mainly Gram-positive bacteria from Lactobacillus genus. Today, probiotics mixtures are commercialized as nutrient supplements (yogurts and other lactic derivatives). After oral administration to humans as yogurt preparations, probiotics form a natural barrier at the intestine against a variety of pathogens. Regarding their use against $H$. pylori, there are several studies on probiotics in the literature describing its application in some aspects with variable results, being a controversial issue. A review by Gotteland et al., 2006 [139] discuss the use of probiotics to control gastric colonization by $H$. pylori.

It has been proposed that probiotics may control $H$. pylori infection considering that some of the Lactobacilli strains may survive in the acidic environment of the human stomach, remaining for some time in that niche. Some strains may produce antimicrobial products such as bacteriocins [140] [141] and other metabolic end products of lactic fermentation (lactic acid, acetic acid) promoting low $\mathrm{pH}$ and affecting growth the of $\mathrm{pH}$ sensitive bacteria [142]. Some Lactobacillus strains may compete with $H$. pylori for adherence to the epithelial cells.

In vitro studies of Chatterjee et al., (2003) [96] revealed that Lactobacillus acidophilus DDS-1J inhibits $H$. pylori growth at 1:1 and higher ratios, but further studies in animal models and humans are required to corroborate these findings in vivo and determine dose range and frequency of dosing.

As a consequence of therapy failure, an increase in the prevalence of antibiot- 
ic-resistant bacteria has arisen, which has led to the search for alternative therapies. Vitor and Vale (2011) [143] have reviewed and discussed alternative therapies for H. pylori, particularly phytotherapy and probiotics. Probiotics are live organisms orally administrated, usually in addition to conventional antibiotic therapy. They may modulate human microbiota and promote health. For instance, probiotics reduce antibiotic side effects [144] [145] [146] [147], strengthen the immune response and compete with pathogenic bacteria [146] [148] [149].

Over the past 8 years, 11 meta-analyses have been published assessing the efficacy of probiotics as adjuvants to cooperate with antibiotics for the eradication of $H$. pylori (Table 3, see [150]). All these studies found that the addition of a probiotic to the antibiotic regimen increased treatment efficacy, with an odds ratio ranging from 1.12 to 2.07. A network meta-analysis performed by Li et al., (2015) [151] came to a similar conclusion. Although probiotic treatment accounted for only a small part of their analyses, they used novel yet robust methodology allowing for indirect comparisons across treatments where a common comparator exists and found that the addition of a probiotic to standard 7-day triple therapy increases eradication rates significantly (OR, 1.14). Demographic factors have been identified as possible predictors of probiotic efficacy, although with conflicting results. Wang et al., (2013) [152] found that, in children, adjuvant probiotics conferred no benefit (OR, 1.08 compared to OR, 2.22 for adults).

Table 3. Meta-analyses of trials examining the efficacy of adjuvant probiotic compounds in Helicobacter pylori eradication therapy.

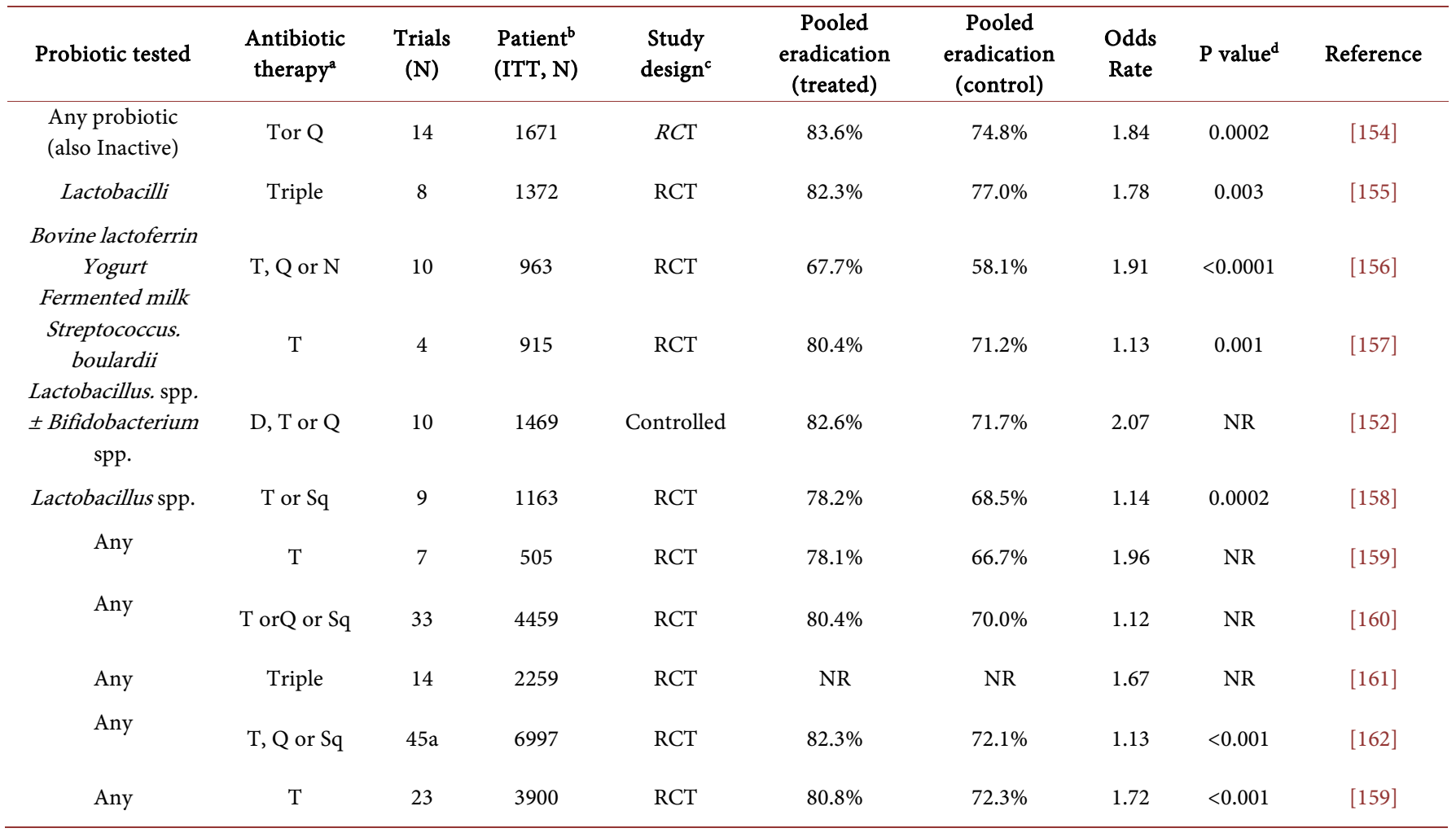

${ }^{\mathrm{a}}$ Type of therapy: $\mathrm{T}=$ triple; $\mathrm{Q}=$ quadruple; $\mathrm{Sq}=$ sequential; $\mathrm{D}=$ dual; $\mathrm{N}=$ none; ${ }^{\mathrm{b}} \mathrm{ITT}=$ intention to treat; $\mathrm{N}=$ not treated; ${ }^{\mathrm{c}} \mathrm{RCT}=$ randomized controlled trial; ${ }^{\mathrm{d}} \mathrm{NR}$ $=$ not reported; ${ }^{\mathrm{e}}$ Includes Chinese literature. 
Boltin et al., 2016 [150] found that studies supporting the use of probiotics in conjunction with antibiotics for the treatment of $H$. pylori infection. Nevertheless, the optimal probiotic species, dose and treatment duration has yet to be determined. Furthermore, the benefit conferred by a probiotic is likely related to efficacy of the antibiotic regimen chosen.

\section{Final Comments}

Nowadays, the prevalence and the emergence of bacterial antibiotic resistances are a very serious problem. Concordantly, the antimicrobial eradication success rate of $H$. pylori has been declining globally in recent years. For example, clarithromycin resistance, in particular, has been rapidly increased in many countries over the past decade, with rates as high as $30 \%$ in both Japan and Italy, $50 \%$ in China and $40 \%$ in Turkey; whereas resistance rates are much lower in Sweden and Taiwan, with a rate of approximately 15\% (Thung et al., 2016). Moreover, to date, there is no large scale production of an effective vaccine against $H$. pylori available in the market (Talebi, 2016) for different reasons as previously and extensively been reviewed by Hongying et al., (2014) [153].

Ancestral folk medicine passed from mouth to mouth for many years and has been wisely applied by "Chamanes" and "Curanderos" in some cases. It has been globally proven by diverse aborigine populations that some natural products obtained from nature can be helpful to alleviate and fight gastrointestinal diseases caused by microorganisms. This knowledge traditionally transferred within these families has been useful to identify the source to isolate and purify new and effective compounds to control many diseases. With the technology available today we can elucidate how folk medicine actually works and understand how it has helped our ancestors for many decades to counteract or reduce disease symptoms since many years ago.

There is a conundrum of components detected in plant extracts that should be studied as potential substitutes or additives in the antibiotic therapy. There are plants and marine algae living in extreme habitats that are able to synthesize bizarre but useful antibacterial compounds to fight the increased number of antibiotic resistant strains. However, the isolation and identification of such compounds responsible for the positive effect on eradication of diverse diseases must be accomplished to test the safety of them and understand their mechanisms of action.

Considering the present situation of a large variety of natural sources with antimicrobial activities further studies will be required to identify the most powerful and useful compounds and test them for toxicity and genotoxic effects on humans before use them to successfully eradicate $H$. pylori from the human stomach.

A comparative study of the antimicrobial activity of different products will be a must in order to use mixtures displaying synergism. Also, the synergism already described between some plant organic compounds and antibiotics could be a very effective alliance. It is also desirable that most of these new products should work in a specific way against pathogenic bacteria without affecting our normal microbiome. 
At present, it is very difficult to compare efficacy among all these products pursuing the same objective against $H$. pylori. In the case of plant derivatives, when using a particular vegetal extract, the amount of active compound extracted will depend on the source, section or organ used as starting material for the isolation, as well as other parameters such as time taking for the extraction, appropriate solvent for the procedure and so on. Moreover, the existence of different $H$. pylori strains does make difficult to compare which extract is better than other. The use of a combination of agents or purified compounds with or without antibiotics could be a faster way to find out a rapid answer to improving the treatment against $H$. pylori. This combined strategy will make more difficult to allow emergence of resistant strains after a treatment with mixed compounds, due to the large chemical differences among these compounds and their biological and physical characteristics.

The intention of this revision was to describe potential alternatives for the treatment of $H$. pylori but due to the great diversity of compounds we cannot provide a clear and define comparative analysis of the different products with antimicrobial activity. In addition, a diet rich in foods having different natural activities anti- $H$. pylori may be an inexpensive but effective collaborator against the rise of antibiotic resistant strains. On the other hand, pharmaceutical companies would be more supportive of development of new drugs based on natural products.

Finally, it is required even more research studies to elucidate the mechanisms of action of these molecules, their synergisms, antagonisms and other pharmacological aspects.

\section{Acknowledgements}

This study was financially supported by the Semilla Funds from the Dirección de Postgrado e Investigación, Universidad Diego Portales, Chile (Project No: 201521).

\section{Disclosure of Interest Statement}

The present study was funded by research funds of the authors. No pharmaceutical grants were used for this study.

\section{References}

[1] Haley, K.P. and Gaddy, J.A. (2015) Helicobacter pylori: Genomic Insight into the HostPathogen Interaction. International Journal of Genomics, 2015, Article ID: 386905. https://doi.org/10.1155/2015/386905

[2] Glupczynski, Y., Megraud, F., Lopez-Brea, M. and Andersen, L.P. (2001) European Multicentre Survey of in Vitro Antimicrobial Resistance in Helicobacter pylori. European Journal of Clinical Microbiology \& Infectious Diseases, 20, 820-823. https://doi.org/10.1007/s100960100611

[3] Graham, D.Y. and Genta, R.M. (2008) Long Term Proton Pump Inhibitor Use and Gastrointestinal Cancer. Current Gastroenterology Reports, 10, 543-547.

http://www.ncbi.nlm.nih.gov/pmc/articles/PMC2838432/

https://doi.org/10.1007/s11894-008-0100-1 
[4] Gisbert, J.P., Trapero, M. and Pajares, J.M. (2005) Evaluation of 3 Different Tests for the Detection of Stool Antigens to Confirm Helicobacter pylori Eradication after Treatment. A pilot study. Gastroenterologia Y Hepatologia, 28, 615-618. https://doi.org/10.1016/S0210-5705(05)71524-7

[5] Talebi Bezmin Abadi, A. (2016) Vaccine against Helicobacter pylori: Inevitable Approach. World Journal of Gastroenterology, 22, 3150-3157. https://doi.org/10.3748/wjg.v22.i11.3150

[6] Wagenaar, J.A., Van Bergen, M.A.P., Mueller, M.A., Wassenaar, T.M. and Carlton, R.M. (2005) Phage Therapy Reduces Campylobacter Jejuni Colonization in Broilers. Veterinary Microbiology, 109, 275-283. https://doi.org/10.1016/j.vetmic.2005.06.002

[7] Ganz, R.A., Viveiros, J., Ahmad, A., Ahmadi, A., Khalil, A. and Tolkoff, M.J. (2005) Helicobacter pylori in Patients Can Be Killed by Visible Light. Lasers in Surgery and Medicine, 36, 260-265. https://doi.org/10.1002/lsm.20161

[8] Hassan, S.T.S. and Zemlicka, M. (2016) Plant-Derived Urease Inhibitors as Alternative Chemotherapeutic Agents. Archiv Der Pharmazie, 349, 507-522.

https://doi.org/10.1002/ardp.201500019

[9] Bonifacio, B.V., dos Santos Ramos, M.A., da Silva, P.B. and Bauab, T.M. (2014) Antimicrobial Activity of Natural Products against Helicobacter pylori: A Review. Annals of Clinical Microbiology and Antimicrobials, 13, 54.

[10] Vale, F.F. and Oleastro, M. (2014) Overview of the Phytomedicine Approaches against $\mathrm{He}$ licobacter pylori, 20, 5594-5609.

[11] Hara, Y. and Ishigami, T. (1989) Antibacterial Activities of Tea Polyphenols against Foodborne Pathogenic Bacteria (Studies on Antibacterial Effects of Tea Polyphenols. Part III) Journal of the Japanese Society of Food Science and Technology, 36, 996-999.

[12] Hara, Y. (1997) Antioxidants in Tea and Their Physiological Functions. In: Hiramatsu, M., Yoshikawa, T. and Inoue, M., Eds., Food and Free Radicals, Springer US, 49-65. http://dx.doi.org/10.1007/978-1-4899-1837-6_5

[13] Mabe, K., Yamada, M., Oguni, I. and Takahashi, T. (1999) In Vitro and In Vivo Activities of Tea Catechins against Helicobacter pylori. Antimicrobial Agents and Chemotherapy, 43, 1788-1791.

[14] Ankolekar, C., Johnson, D., Pinto, M.daS., Johnson, K., Labbe, R. and Shetty, K. (2011) Inhibitory Potential of Tea Polyphenolics and Influence of Extraction Time against Helicobacter pylori and Lack of Inhibition of Beneficial Lactic Acid Bacteria. Journal of Medicinal Food, 14, 1321-1329. https://doi.org/10.1089/jmf.2010.0237

[15] Boyanova, L., Gergova, G., Nikolov, R., Derejian, S., Lazarova, E. and Katsarov, N. (2005) Activity of Bulgarian Propolis against 94 Helicobacter pylori Strains in Vitro by Agar-Well Diffusion, Agar Dilution and Disc Diffusion Methods. Journal of Medical Microbiology, 54, 481-483. https://doi.org/10.1099/jmm.0.45880-0

[16] Boyanova, L. (2014) Comparative Evaluation of the Activity of Plant Infusions against $\mathrm{He}$ licobacter pylori Strains by Three Methods. World Journal of Microbiology \& Biotechnology, 30, 1633-1637. https://doi.org/10.1007/s11274-013-1589-5

[17] Boyanova, L., Ilieva, J., Gergova, G., Vladimirov, B., Nikolov, R. and Mitov, I. (2015) Honey and Green/Black Tea Consumption May Reduce the Risk of Helicobacter pylori Infection. Diagnostic Microbiology and Infectious Disease, 82, 85-86. https://doi.org/10.1016/j.diagmicrobio.2015.03.001

[18] Bankova, V., De Castro, S. and Marcucci, M. (2000) Propolis: Recent Advances in Chemistry and Plant Origin. Apidologie, 31, 3-15.

[19] Burdock, G.A. (1998) Review of the Biological Properties and Toxicity of Bee Propolis 
(Propolis). Food and Chemical Toxicology, 36, 347-363.

https://doi.org/10.1016/S0278-6915(97)00145-2

[20] Stepanovic, S., Antic, N., Dakic, I. and Svabic-Vlahovic, M. (2003) In Vitro Antimicrobial Activity of Propolis and Synergism between Propolis and Antimicrobial Drugs. Microbiological Research, 158, 353-357. https://doi.org/10.1078/0944-5013-00215

[21] Mirzoeva, O.K., Grishanin, R.N. and Calder, P.C. (1997) Antimicrobial Action of Propolis and Some of Its Components: The Effects on Growth, Membrane Potential and Motility of Bacteria. Microbiological Research, 152, 239-246. https://doi.org/10.1016/S0944-5013(97)80034-1

[22] Drago, L., Mombelli, B., De Vecchi, E., Fassina, M.C., Tocalli, L. and Gismondo, M.R. (2000) In Vitro Antimicrobial Activity of Propolis Dry Extract. Journal of Chemotherapy 12, 390-395. https://doi.org/10.1179/joc.2000.12.5.390

[23] Nostro, A., Cellini, L., Di Bartolomeo, S., Cannatelli, M.A., Di Campli, E. and Procopio, F. (2006) Effects of Combining Extracts (from Propolis or Zingiber officinale) with Clarithromycin on Helicobacter pylori. Phytotherapy Research, 20, 187-190. https://doi.org/10.1002/ptr.1830

[24] Cui, K., Lu, W., Zhu, L., Shen, X. and Huang, J. (2013) Caffeic Acid Phenethyl Ester (CAPE), an Active Component of Propolis, Inhibits Helicobacter pylori Peptide Deformylase Activity. Biochemical and Biophysical Research Communications, 435, 289-294. https://doi.org/10.1016/j.bbrc.2013.04.026

[25] Baltas, N., Karaoglu, S.A., Tarakci, C. and Kolayli, S. (2016) Effect of Propolis in Gastric Disorders: Inhibition Studies on the Growth of Helicobacter pylori and Production of Its Urease. Journal of Enzyme Inhibition and Medicinal Chemistry, 27, 1-5. https://doi.org/10.1080/14756366.2016.1186023

[26] Yun, T.K. and Choi, S.Y. (1995) Preventive Effect of Ginseng Intake against Various Human Cancers: A Case-Control Study On 1987 Pairs. Cancer Epidemiology, Biomarkers \& Prevention, 4, 401-408.

[27] Yun, T.-K. (2003) Experimental and Epidemiological Evidence on Non-Organ Specific Cancer Preventive Effect of Korean Ginseng and Identification of Active Compounds. $\mathrm{Mu}$ tation Research, 523-524, 63-74. https://doi.org/10.1016/S0027-5107(02)00322-6

[28] Bae, E.A., Han, M.J., Baek, N.I. and Kim, D.H. (2001) In Vitro Anti-Helicobacter pylori Activity of Panaxytriol Isolated from Ginseng. Archives of Pharmacal Research, 24, 297-299. https://doi.org/10.1007/BF02975095

[29] Park, S. and Jin, J.-H. (2005) Rescue of Helicobacter pylori-Induced Cytotoxicity by Red Ginseng. Digestive Diseases and Sciences, 50, 1218-1227. https://doi.org/10.1007/s10620-005-2763-x

[30] Bae, M., Lim, J.W. and Kim, H. (n.d.-ad) Effect of Korean Red Ginseng on Helicobacter pylori-Induced Expression of Inflammatory Mediators in Gastric Mucosa of Mongolian Gerbil. The FASEB Journal, 25, 773.7-773.7. http://www.fasebj.org/content/25/1_Supplement/773.7.abstract

[31] Han, Y.-M., Park, J.-M., Jeong, M., Yoo, J.-H., Kim, W.-H. and Shin, S.-P. (2015) Dietary, Non-Microbial Intervention to Prevent Helicobacter pylori-Associated Gastric Diseases. Annals of Translational Medicine, 3, 122.

[32] Cho, S.O., Lim, J.W. and Kim, H. (2013) Red Ginseng Extract Inhibits the Expression of MCP-1 and iNOS in Helicobacter pylori-Infected Gastric Epithelial Cells by Suppressing the Activation of NADPH Oxidase and Jak2/Stat3. Journal of Ethnopharmacology, 150, 761-764. https://doi.org/10.1016/j.jep.2013.09.013 
[33] Bae, M., Jang, S., Lim, J.W., Kang, J., Bak, E.J., Cha, J.-H. and Kim, H. (2014) Protective Effect of Korean Red Ginseng Extract against Helicobacter pylori-Induced Gastric Inflammation in Mongolian Gerbils. Journal of Ginseng Research, 38, 8-15.

https://doi.org/10.1016/j.jgr.2013.11.005

[34] Jin, X., Che, D.-B., Zhang, Z.-H., Yan, H.-M., Jia, Z.-Y. and Jia, X.-B. (2016) Ginseng Consumption and Risk of CANCER: A Meta-Analysis. Journal of Ginseng Research, 40, 269-277. https://doi.org/10.1016/j.jgr.2015.08.007

[35] Pasteur, L. (1857) Mémoire sur la fermentation appelée lactique (Extrait des l'auteur). Comptes Rendus Des Séances de I'Academie Des Sciences, 45, 913-916.

[36] Cavallito, C.J. and Bailey, J.H. (1944) Allicin, the Antibacterial Principle of Allium sativum. I. Isolation, Physical Properties and Antibacterial Action. Journal of the American Chemical Society, 66, 1950-1951. https://doi.org/10.1021/ja01239a048

[37] Cellini, L., Di Campli, E., Masulli, M., Di Bartolomeo, S. and Allocati, N. (1996) Inhibition of Helicobacter pylori by Garlic Extract (Allium sativum). FEMS Immunology and Medical Microbiology, 13, 273-277. https://doi.org/10.1111/j.1574-695X.1996.tb00251.x

[38] Sivam, G.P., Lampe, J.W., Ulness, B., Swanzy, S.R. and Potter, J.D. (1997) Helicobacter pylori-In Vitro Susceptibility to Garlic (Allium sativum) Extract. Nutrition and Cancer, 27, 118-121. https://doi.org/10.1080/01635589709514512

[39] Tang, H.R., Fan, Y.J. and Liu, S. (2014) Helicobacter pylori Infection and Associated Risk Factors in Chengdu. Sichuan Da Xue Xue Bao Yi Xue Ban, 45, 823-826.

[40] Reuter, H.D., Koch, H.P. and Lawson, D. (1996) Therapeutic Effects and Applications of Garlic and Its Preparations. In: Lawson, L.D. and Koch, H.P., Eds., Garlic. The Science and Therapeutic Applications of Allium sativum L. and Related Species, 2nd Edition, William \& Wilkins, Baltimore, 135-212.

[41] Fortunatov, M.N. (1955) On the Activity of the Phytoncides from Garlic in the Human Organism upon Peroral Administration. Farmakol Toksikol, 18, 43-46.

[42] Lawson, L.D. and Hughes, B.G. (1992) Characterization of the Formation of Allicin and Other Thiosulfinates from Garlic. Planta Medica, 58, 345-350.

https://doi.org/10.1055/s-2006-961482

[43] O’Gara, E.A., Hill, D.J. and Maslin, D.J. (2000) Activities of Garlic Oil, Garlic Powder, and Their Diallyl Constituents against Helicobacter pylori. Applied and Environmental Microbiology, 66, 2269-2273. https://doi.org/10.1128/AEM.66.5.2269-2273.2000

[44] Lawson, L. (1998) Garlic: A Review of Its Medicinal Effects and Indicated Active Compounds. In: Lawson, L.S., Ed., Phytomedicines of Europe: Chemistry and Biological Activity, ACS Symposium Series 691, Am. Chem. Soc., Washington, 176-209.

[45] Chung, J.G., Chen, G.W., Wu, L.T., Chang, H.L., Lin, J.G., Yeh, C.C. and Wang, T.F. (1998) Effects of Garlic Compounds Diallyl Sulfide and Diallyl disulfide on Arylamine N-Acetyltransferase Activity in Strains of Helicobacter pylori from Peptic Ulcer Patients. The American Journal of Chinese Medicine, 26, 353-364. https://doi.org/10.1142/S0192415X98000397

[46] Chung, J.G. (1999) The Effects of Vitamin E on Arylamine N-Acetyltransferase Activity in Strains of Helicobacter pylori from Peptic Ulcer Patients. Food and Chemical Toxicology, 37, 655-661. https://doi.org/10.1016/S0278-6915(99)00047-2

[47] Zaidi, S.F., Muhammad, J.S., Usmanghani, K. and Sugiyama, T. (2015) Review: Pharmacological Ins and Outs of Medicinal Plants against Helicobacter pylori: A Review. Pakistan Journal of Pharmaceutical Sciences, 28, 1171-1176.

[48] Tabak, M., Armon, R. and Neeman, I. (1999) Cinnamon Extracts' Inhibitory Effect on He- 
licobacter pylori. Journal of Ethnopharmacology, 67, 269-277.

https://doi.org/10.1016/S0378-8741(99)00054-9

[49] Nir, Y., Potasman, I., Stermer, E., Tabak, M. and Neeman, I. (2000) Controlled Trial of the Effect of Cinnamon Extract on Helicobacter pylori. Helicobacter, 5, 94-97.

https://doi.org/10.1046/j.1523-5378.2000.00014.x

[50] Muhammad, J.S., Zaidi, S.F., Shaharyar, S., Refaat, A., Usmanghani, K., Saiki, I. and Sugiyama, T. (2015) Anti-Inflammatory Effect of Cinnamaldehyde in Helicobacter pylori Induced Gastric Inflammation. Biological \& Pharmaceutical Bulletin, 38, 109-115. https://doi.org/10.1248/bpb.b14-00609

[51] Chatterjee, A., Yasmin, T., Bagchi, D. and Stohs, S.J. (2004) Inhibition of Helicobacter pylori in Vitro by Various Berry Extracts, with Enhanced Susceptibility to Clarithromycin. Molecular and Cellular Biochemistry, 265, 19-26. https://doi.org/10.1023/B:MCBI.0000044310.92444.ec

[52] Amin, M., Anwar, F., Janjua, M.R.S.A., Iqbal, M.A. and Rashid, U. (2012) Green Synthesis of Silver Nanoparticles through Reduction with Solanum xanthocarpum L. Berry Extract: Characterization, Antimicrobial and Urease Inhibitory Activities against Helicobacter pylori. International Journal of Molecular Sciences, 13, 9923-9941. https://doi.org/10.3390/ijms13089923

[53] Nostro, A., Cellini, L., Di Bartolomeo, S., Di Campli, E., Grande, R., Cannatelli, M.A. (2005) Antibacterial Effect of Plant Extracts against Helicobacter pylori. Phytotherapy Research, 19, 198-202. https://doi.org/10.1002/ptr.1640

[54] Germano, M.P., Sanogo, R., Guglielmo, M., De Pasquale, R., Crisafi, G. and Bisignano, G. (1998) Effects of Pteleopsis suberosa Extracts on Experimental Gastric Ulcers and Helicobacter pylori Growth. Journal of Ethnopharmacology, 59, 167-172. https://doi.org/10.1016/S0378-8741(97)00109-8

[55] Adeniyi, B.A. and Anyiam, F.M. (2004) In Vitro Anti-Helicobacter pylori Potential of Methanol Extract of Allium ascalonicum linn. (Liliaceae) Leaf: Susceptibility and Effect on Urease Activity. Phytotherapy Research, 18, 358-361. https://doi.org/10.1002/ptr.1265

[56] Nariman, F., Eftekhar, F., Habibi, Z. and Falsafi, T. (2004) Anti-Helicobacter pylori Activities of Six Iranian Plants. Helicobacter, 9, 146-151. https://doi.org/10.1111/j.1083-4389.2004.00211.x

[57] Malekzadeh, F., Ehsanifar, H., Shahamat, M., Levin, M. and Colwell, R.R. (2001) Antibacterial Activity of Black Myrobalan (Terminalia chebula Retz) against Helicobacter pylori. International Journal of Antimicrobial Agents, 18, 85-88. https://doi.org/10.1016/S0924-8579(01)00352-1

[58] Li, Y., Xu, C., Zhang, Q., Liu, J.Y. and Tan, R.X. (2005) In Vitro Anti-Helicobacter pylori action of 30 Chinese Herbal Medicines Used to Treat Ulcer Diseases. Journal of Ethnopharmacology, 98, 329-333. https://doi.org/10.1016/j.jep.2005.01.020

[59] Shahani, S., Monsef-Esfahani, H.R., Saeidnia, S., Saniee, P., Siavoshi, F. and Foroumadi, A., (2012) Anti-Helicobacter pylori Activity of the Methanolic Extract of Geum iranicum and Its Main Compounds. Naturforsch C, 67, 172-180.

https://doi.org/10.5560/ZNC.2012.67c0172

[60] Silva, O., Viegas, S., de Mello-Sampayo, C., Costa, M.J.P., Serrano, R., Cabrita, J. and Gomes, E.T. (2012) Anti-Helicobacter pylori Activity of Terminalia macroptera Root. Fitoterapia, 83, 872-876. https://doi.org/10.1016/j.fitote.2012.03.019

[61] Pinheiro Silva, L., Damacena de Angelis, C., Bonamin, F., Kushima, H., Jose Mininel, F. and Campaner Dos Santos, L. (2015) Terminalia catappa L.: A Medicinal Plant from the Carib- 
bean Pharmacopeia with Anti-Helicobacter pylori and Antiulcer Action in Experimental Rodent Models. Journal of Ethnopharmacology, 159, 285-295.

https://doi.org/10.1016/j.jep.2014.11.025

[62] Ranilla, L.G., Apostolidis, E. and Shetty, K. (2012) Antimicrobial Activity of an Amazon Medicinal Plant (Chancapiedra) (Phyllanthus niruri L.) against Helicobacter pylori and Lactic Acid Bacteria. Phytotherapy Research, 26, 791-799.

https://doi.org/10.1002/ptr.3646

[63] Lemos, L.M.S., Martins, T.B., Tanajura, G.H., Gazoni, V.F., Bonaldo, J. and Strada, C.L. (2012) Evaluation of Antiulcer Activity of Chromanone Fraction from Calophyllum brasiliense Camb. Journal of Ethnopharmacology, 141, 432-439.

https://doi.org/10.1016/j.jep.2012.03.006

[64] Lawal, T.O., Adeniyi, B.A., Moody, J.O. and Mahady, G.B. (2012) Combination Studies of Eucalyptus torelliana F. Muell. Leaf Extracts and Clarithromycin on Helicobacter pylori. Phytotherapy Research, 26, 1393-1398. https://doi.org/10.1002/ptr.3719

[65] Njume, C., Afolayan, A.J., Samie, A. and Ndip, R.N. (2011) Inhibitory and Bactericidal Potential of Crude Acetone Extracts of Combretum molle (Combretaceae) on Drug-Resistant Strains of Helicobacter pylori. Journal of Health, Population, and Nutrition, 29, 438-445. https://doi.org/10.3329/jhpn.v29i5.8897

[66] Suk, K.T., Baik, S.K., Kim, H.S., Park, S.M., Paeng, K.J. and Uh, Y. (2011) Antibacterial Effects of the Urushiol Component in the Sap of the Lacquer Tree (Rhus verniciflua Stokes) on Helicobacter pylori. Helicobacter, 16, 434-443. https://doi.org/10.1111/j.1523-5378.2011.00864.x

[67] Amin, M., Anwar, F., Naz, F., Mehmood, T. and Saari, N. (2013) Anti-Helicobacter pylori and Urease Inhibition Activities of Some Traditional Medicinal Plants. Molecules, 18, 2135-2149. https://doi.org/10.3390/molecules18022135

[68] Zhang, X.Q., Gu, H.M., Li, X.Z., Xu, Z.N. and Chen, Y.S. (2013) Anti-Helicobacter pylori Compounds from the Ethanol Extracts of Geranium wilfor dii. Journal of Ethnopharmacology, 147, 204-207. https://doi.org/10.1016/j.jep.2013.02.032

[69] da Silva Junior, I.F., Balogun, S.O., de Oliveira, R.G., Damazo, A.S. and Martins, D.T. de O. (2016) Piper umbellatum L.: A Medicinal Plant with Gastric-Ulcer Protective and Ulcer Healing Effects in Experimental Rodent Models. Journal of Ethnopharmacology, 192, 123-131. https://doi.org/10.1016/j.jep.2016.07.011

[70] Tabak, M., Armon, R., Potasman, I. and Neeman I. (1996) In Vitro Inhibition of Helicobacter pylori by Extracts of Thyme. Journal of Applied Bacteriology, 80, 667-672. https://doi.org/10.1111/j.1365-2672.1996.tb03272.x

[71] Wang, H.H., Chung, J.G., Ho, C.C., Wu, L.T. and Chang, S.H. (1998) Aloe-Emodin Effects on Arylamine N-Acetyltransferase Activity in the Bacterium Helicobacter pylori. Planta Medica, 64, 176-178. https://doi.org/10.1055/s-2006-957399

[72] Bae, E.A., Han, M.J., Kim, N.J. and Kim, D.H. (1998) Anti-Helicobacter pylori Activity of Herbal Medicines. Biological \& Pharmaceutical Bulletin, 21, 990-992. https://doi.org/10.1248/bpb.21.990

[73] Gadhi, C.A., Benharref, A., Jana, M. and Lozniewski, A. (2001) Anti-Helicobacter pylori Activity of Aristolochia paucinervis Pomel Extracts. Journal of Ethnopharmacology, 75, 203-205. https://doi.org/10.1016/S0378-8741(01)00184-2

[74] Wang, Y.-C. and Huang, T.-L. (2005) Anti-Helicobacter pylori Activity of Plumbago zeylanica L. FEMS Immunology and Medical Microbiology, 43, 407-412. https://doi.org/10.1016/j.femsim.2004.10.015 
[75] Guarim-Neto, G. (2006) O saber tradicional pantaneiro: As plantas medicinais e a educação ambiental. Rev. Eletrônica Mestr. Educ. Ambient., 17, 71-89.

[76] Reyes-Chilpa, R., Baggio, C.H., Alavez-Solano, D., Estrada-Muñiz, E., Kauffman, F.C. and Sanchez, R.I. (2006) Inhibition of Gastric H+,K+-ATPase Activity by Flavonoids, Coumarins and Xanthones Isolated from Mexican Medicinal Plants. Journal of Ethnopharmacology, 105, 167-172. https://doi.org/10.1016/j.jep.2005.10.014

[77] Paraschos, S., Mitakou, S. and Skaltsounis, A.-L. (2012) Chios Gum Mastic: A Review of Its Biological Activities. Current Medicinal Chemistry, 19, 2292-2302. https://doi.org/10.2174/092986712800229014

[78] Ferreira, S., Santos, J., Duarte, A., Duarte, A.P., Queiroz, J.A. and Domingues, F.C. (2012) Screening of Antimicrobial Activity of Cistus ladanifer and Arbutus unedo Extracts. Natural Product Research, 26, 1558-1560. https://doi.org/10.1080/14786419.2011.569504

[79] .Krivokuca, M., Niketic, M., Milenkovic, M., Golic, N., Masia, C. and Scaltrito, M.M. (2015) Anti-Helicobacter pylori Activity of Four Alchemilla Species (Rosaceae). Natural Product Communications, 10, 1369-1371.

[80] Al-Zoreky, N.S. (2009) Antimicrobial Activity of Pomegranate (Punica granatum L.) Fruit Peels. International Journal of Food Microbiology, 134, 244-248. https://doi.org/10.1016/j.ijfoodmicro.2009.07.002

[81] Duman, A.D., Ozgen, M., Dayisoylu, K.S., Erbil, N. and Durgac, C. (2009) Antimicrobial Activity of Six Pomegranate (Punica granatum L.) Varieties and Their Relation to Some of Their Pomological and Phytonutrient Characteristics. Molecules (Basel, Switzerland), 14, 1808-1817. https://doi.org/10.3390/molecules14051808

[82] Aynehchi, Y., Sormaghi, M.H., Shirudi, M. and Souri, E. (1982) Screening of Iranian Plants for Antimicrobial Activity. Acta Pharmaceutica Suecica, 19, 303-308.

[83] Prashanth, D., Asha, M.K. and Amit, A. (2001) Antibacterial Activity of Punica granatum. Fitoterapia, 72, 171-173. https://doi.org/10.1016/S0367-326X(00)00270-7

[84] Machado, T.B., Pinto, A.V., Pinto, M.C.F.R., Leal, I.C.R., Silva, M.G. and Amaral, A.C.F. (2003) In Vitro Activity of Brazilian Medicinal Plants, Naturally Occurring Naphthoquinones and Their Analogues, against Methicillin-Resistant Staphylococcus aureus. International Journal of Antimicrobial Agents, 21, 279-284. https://doi.org/10.1016/S0924-8579(02)00349-7

[85] Rani, P. (2004) Khullar Evaluation of Some Medicinal Plants for Their Anti-Enteric Potential against Multi-Drug Resistant Salmonella typhi. Phytotherapy Research, 18, 670-673. https://doi.org/10.1002/ptr.1522

[86] Ismail, T., Sestili, P. and Akhtar, S. (2012) Pomegranate Peel and Fruit Extracts: A Review of Potential Anti-Inflammatory and Anti-Infective Effects. Journal of Ethnopharmacology, 143, 397-405. https://doi.org/10.1016/j.jep.2012.07.004

[87] Menezes, S.M.S., Cordeiro, L.N. and Viana, G.S.B. (2006) Punica granatum (Pomegranate) Extract Is Active against Dental Plaque. Journal of Herbal Pharmacotherapy, 6, 79-92. https://doi.org/10.1080/J157v06n02_07

[88] Vasconcelos, L.C., Sampaio, M.C., Sampaio, F.C. and Higino, J.S (2003) Use of Punica granatum as an Antifungal Agent against Candidosis Associated with Denture Stomatitis. Mycoses, 46, 192-196. https://doi.org/10.1046/j.1439-0507.2003.00884.x

[89] Sastravaha, G., Yotnuengnit, P., Booncong, P. and Sangtherapitikul, P. (2003) Adjunctive Periodontal Treatment with Centella asiatica and Punica granatum Extracts. A Preliminary Study. Journal of the International Academy of Periodontology, 5, 106-115.

[90] Sastravaha, G., Gassmann, G. and Sangtherapitikul, P. and Grimm, W. D. (2005) Adjuntive 
Periodontal Treatment with Centella asiatica and Punica granatum Extracts in Supportive Periodontal Therapy. Journal of the International Academy of Periodontology, 7, 70-79.

[91] Braga, L.C., Leite, A.A.M., Xavier, K.G.S., Takahashi, J.A., Bemquerer, M.P. and Chartone-Souza, E. (2005) Synergic Interaction between Pomegranate Extract and Antibiotics against Staphylococcus aureus. Canadian Journal of Microbiology, 51, 541-547.

https://doi.org/10.1139/w05-022

[92] Hajimahmoodi, M., Shams-Ardakani, M., Saniee, P., Siavoshi, F., Mehrabani, M. and Hosseinzadeh, H. (2011) In Vitro Antibacterial Activity of Some Iranian Medicinal Plant Extracts against Helicobacter pylori. Natural Product Research, 25, 1059-1066. https://doi.org/10.1080/14786419.2010.501763

[93] Haghayeghi, K., Shetty, K. and Labbe, R. (2013) Inhibition of Foodborne Pathogens by Pomegranate Juice. Journal of Medicinal Food, 16, 467-470. https://doi.org/10.1089/jmf.2012.0233

[94] Lo, H.H. and Chung, J.G. (1999) The Effects of Plant Phenolics, Caffeic Acid, Chlorogenic acid and Ferulic Acid on Arylamine N-Acetyltransferase Activities in Human Gastrointestinal Microflora. Anticancer Research, 19, 133-139.

[95] Chuang, C.-H., Sheu, B.-S., Huang, A.-H., Yang, H.-B. and Wu, J.-J. (2002) Vitamin C and E Supplements to Lansoprazole-Amoxicillin-Metronidazole Triple Therapy May Reduce the Eradication Rate of Metronidazole-Susceptible Helicobacter pylori Infection. Helicobacter, 7, 310-316. https://doi.org/10.1046/j.1523-5378.2002.00095.x

[96] Chatterjee, A., Yasmin, T., Bagchi, D. and Stohs, S.J. (2003) The Bactericidal Effects of Lactobacillus acidophilus, Garcinol and Protykin Compared to Clarithromycin, on Helicobacter pylori. Molecular and Cellular Biochemistry, 243, 29-35. https://doi.org/10.1023/A:1021649427988

[97] Matsubara, S., Shibata, H., Ishikawa, F., Yokokura, T., Takahashi, M. and Sugimura, T. (2003) Suppression of Helicobacter pylori-Induced Gastritis by Green Tea Extract in Mongolian Gerbils. Biochemical and Biophysical Research Communications, 310, 715-719. https://doi.org/10.1016/j.bbrc.2003.09.066

[98] Yanaka, A., Fahey, J.W., Fukumoto, A., Nakayama, M., Inoue, S. and Zhang, S. (2009) Dietary Sulforaphane-Rich Broccoli Sprouts Reduce Colonization and Attenuate Gastritis in Helicobacter pylori-Infected Mice and Humans. Cancer Prevention Research, 2, 353-360. https://doi.org/10.1158/1940-6207.CAPR-08-0192

[99] Fahey, J.W., Haristoy, X., Dolan, P.M., Kensler, T.W., Scholtus, I. and Stephenson, K.K. (2002) Sulforaphane Inhibits Extracellular, Intracellular, and Antibiotic-Resistant Strains of Helicobacter pylori and Prevents Benzo[a]pyrene-Induced Stomach Tumors. Proceedings of the National Academy of Sciences of the United States of America, 99, 7610-7615. https://doi.org/10.1073/pnas.112203099

[100] Conzatti, A., Froes, F.C., Schweigert Perry, I.D. and Souza, C.G. (2014) Clinical and Molecular Evidence of the Consumption of Broccoli, Glucoraphanin and Sulforaphane in $\mathrm{Hu}$ mans. Nutricion Hospitalaria, 31, 559-569.

[101] Bae, E.A., Han, M.J. and Kim, D.H. (1999) In Vitro Anti-Helicobacter pylori Activity of Some Flavonoids and Their Metabolites. Planta Medica, 65, 442-443.

https://doi.org/10.1055/s-2006-960805

[102] Fukai, T., Marumo, A., Kaitou, K., Kanda, T., Terada, S. and Nomura, T. (2002) Anti-Helicobacter pylori Flavonoids from Licorice Extract. Life Sciences, 71, 1449-1463. https://doi.org/10.1016/S0024-3205(02)01864-7

[103] Fahey, J.W., Stephenson, K.K., Wade, K.L. and Talalay, P. (2013) Urease from Helicobacter 
pylori Is Inactivated by Sulforaphane and Other Isothiocyanates. Biochemical and Biophysical Research Communications, 435, 1-7. https://doi.org/10.1016/j.bbrc.2013.03.126

[104] Lee, H.-K., Song, H.E., Lee, H.-B., Kim, C.-S., Koketsu, M. and Ngan, L.T.M. (2014) Growth Inhibitory, Bactericidal, and Morphostructural Effects of Dehydrocostus Lactone from Magnolia sieboldii Leaves on Antibiotic-Susceptible and -Resistant Strains of Helicobacter pylori. PloS One, 9, Article ID: e95530. https://doi.org/10.1371/journal.pone.0095530

[105] Isobe, T., Doe, M., Morimoto, Y., Nagata, K. and Ohsaki, A. (2006) The Anti-Helicobacter pylori Flavones in a Brazilian Plant, Hyptis fasciculata, and the Activity of Methoxyflavones. Biological \& Pharmaceutical Bulletin, 29, 1039-1041.

https://doi.org/10.1248/bpb.29.1039

[106] Bae, E.A., Han, M.J. and Kim, D.H. (2001) In Vitro Anti-Helicobacter Pylori Activity of Irisolidone Isolated from the Flowers and Rhizomes of Pueraria thunbergiana. Planta Medica, 67, 161-163.

[107] Ramanathan, R., Das, N.P. and Tan, C.H. (1994) Effects of Gamma-Linolenic Acid, Flavonoids, and Vitamins on Cytotoxicity and Lipid Peroxidation. Free Radical Biology \& Medicine, 16, 43-48. https://doi.org/10.1016/0891-5849(94)90241-0

[108] Chung, J.G., Hsia, T.C., Kuo, H.M., Li, Y.C., Lee, Y.M. and Lin, S.S. (2001) Inhibitory Actions of Luteolin on the Growth and Arylamine N-Acetyltransferase Activity in Strains of Helicobacter pylori from Ulcer Patients. Toxicology in Vitro, 15, 191-198. https://doi.org/10.1016/S0887-2333(01)00015-7

[109] Post, J.F. and Varma, R.S. (1992) Growth Inhibitory Effects of Bioflavonoids and Related Compounds on Human Leukemic CEM-C1 and CEM-C7 Cells. Cancer Letters, 67, 207213. https://doi.org/10.1016/0304-3835(92)90145-L

[110] Matsukawa, Y., Marui, N., Sakai, T., Satomi, Y., Yoshida, M. and Matsumoto, K. (1993) Genistein Arrests Cell Cycle Progression at G2-M. Cancer Research, 53, 1328-1331.

[111] Ryu, S.Y., Choi, S.U., Lee, C.O., Ahn, J.W. and Lee, S.H. (1994) Zee Activity of Some Phenolic Components in Plants. Archives of Pharmacal Research, 17, 42-44. https://doi.org/10.1007/BF02978247

[112] Pettit, G.R., Hoard, M.S., Doubek, D.L., Schmidt, J.M., Pettit, R.K. and Tackett, L.P. (1996) Antineoplastic Agents 338. The Cancer Cell Growth Inhibitory. Constituents of Terminalia arjuna (Combretaceae). Journal of Ethnopharmacology, 53, 57-63. https://doi.org/10.1016/S0378-8741(96)01421-3

[113] Yahiro, K., Shirasaka, D., Tagashira, M., Wada, A., Morinaga, N. and Kuroda, F. (2005) Inhibitory Effects of Polyphenols on Gastric Injury by Helicobacter pylori VacA Toxin. Helicobacter, 10, 231-239. https://doi.org/10.1111/j.1523-5378.2005.00315.x

[114] Asha, M.K., Debraj, D., Prashanth, D., Edwin, J.R., Srikanth, H.S., Muruganantham, N. (2013) In Vitro Anti-Helicobacter pylori Activity of a Flavonoid Rich Extract of Glycyrrhiza glabra and Its Probable Mechanisms of Action. Journal of Ethnopharmacology, 145, 581-586. https://doi.org/10.1016/j.jep.2012.11.033

[115] Sekiguchi, H., Takabayashi, F., Irie, K. and Murakami, A. (2012) Auraptene Attenuates Gastritis via Reduction of Helicobacter pylori Colonization and Pro-Inflammatory Mediator Production in C57BL/6 Mice. Journal of Medicinal Food, 15, 658-663. https://doi.org/10.1089/jmf.2011.1844

[116] Paracatu, L.C., Bonacorsi, C., de Farias, C.M.Q.G., Nazare, A.C., Petronio, M.S. and Regasini, L.O. (2014) Alkyl Caffeates as Anti-Helicobacter pylori and Scavenger of Oxidants Produced by Neutrophils. Medicinal Chemistry (Shariqah), 10, 74-80. https://doi.org/10.2174/157340641001131226125042 
[117] Ohno, T., Kita, M., Yamaoka, Y., Imamura, S., Yamamoto, T. and Mitsufuji, S. (2003) Antimicrobial Activity of Essential Oils against Helicobacter pylori. Helicobacter, 8, 207-215. https://doi.org/10.1046/j.1523-5378.2003.00146.x

[118] Drago, L., Mombelli, B., Ciardo, G., De Vecchi, E. and Gismondo, M.R. (1999) Effects of Three Different Fish Oil Formulations on Helicobacter pylori Growth and Viability: In Vitro Study. Journal of Chemotherapy (Florence, Italy), 11, 207-210.

https://doi.org/10.1179/joc.1999.11.3.207

[119] Canizares, P., Gracia, I., Gomez, L.A., Martin de Argila, C., de Rafael, L. and Garcia, A. (2002) Optimization of Allium sativum Solvent Extraction for the Inhibition of in Vitro Growth of Helicobacter pylori. Biotechnology Progress, 18, 1227-1232. https://doi.org/10.1021/bp025592z

[120] O'Gara, E.A., Maslin, D.J., Nevill, A.M. and Hill, D.J. (2008) The Effect of Simulated Gastric Environments on the Anti-Helicobacter Activity of Garlic Oil. Journal of Applied Microbiology, 104, 1324-1331. https://doi.org/10.1111/j.1365-2672.2007.03637.x

[121] Falsafi, T., Moradi, P., Mahboubi, M., Rahimi, E., Momtaz, H. and Hamedi, B. (2015) Chemical Composition and Anti-Helicobacter pylori Effect of Satureja bachtiarica Bunge Essential Oil. Phytomedicine: International Journal of Phytotherapy and Phytopharmacology, 22, 173-177. https://doi.org/10.1016/j.phymed.2014.11.012

[122] Miyamoto, T., Okimoto, T. and Kuwano, M. (2014) Chemical Composition of the Essential Oil of Mastic Gum and their Antibacterial Activity against Drug-Resistant Helicobacter pylori. Natural Products and Bioprospecting, 4, 227-231. https://doi.org/10.1007/s13659-014-0033-3

[123] Huang, M.T., Wood, A.W., Newmark, H.L., Sayer, J.M., Yagi, H. and Jerina, D.M. (1983) Inhibition of the Mutagenicity of Bay-Region Diol-Epoxides of Polycyclic Aromatic Hydrocarbons by Phenolic Plant Flavonoids. Carcinogenesis, 4, 1631-1637.

https://doi.org/10.1093/carcin/4.12.1631

[124] Shin, J.E., Kim, J.M., Bae, E.A., Hyun, Y.J. and Kim, D.H. (2005) In Vitro Inhibitory Effect of Flavonoids on Growth, Infection and Vacuolation of Helicobacter pylori. Planta Medica, 71, 197-201. https://doi.org/10.1055/s-2005-837816

[125] Beswick, E.J., Pinchuk, I.V, Minch, K., Suarez, G., Sierra, J.C. and Yamaoka, Y. (2006) The Helicobacter pylori Urease B Subunit Binds to CD74 on Gastric Epithelial Cells and Induces NF-kappaB Activation and Interleukin-8 Production. Infection and Immunity, 74, 1148-1155. https://doi.org/10.1128/IAI.74.2.1148-1155.2006

[126] Imai, H., Osawa, K., Yasuda, H., Hamashima, H., Arai, T. and Sasatsu, M. (2001) Inhibition by the Essential Oils of Peppermint and Spearmint of the Growth of Pathogenic Bacteria. Microbios, 106, 31-39.

[127] Kalpoutzakis, E., Aligiannis, N., Mentis, A., Mitaku, S. and Charvala, C. (2001) Composition of the Essential Oil of Two Nepeta Species and In Vitro Evaluation of Their Activity against Helicobacter pylori. Planta Medica, 67, 880-883.

https://doi.org/10.1055/s-2001-18851

[128] Frieri, G., Pimpo, M.T., Palombieri, A., Melideo, D., Marcheggiano, A. and Caprilli, R. (2000) Polyunsaturated Fatty Acid Dietary Supplementation: An Adjuvant Approach to Treatment of Helicobacter pylori Infection. Nutrition Research, 20, 907-916. https://doi.org/10.1016/S0271-5317(00)00182-2

[129] Keenan, J.I., Salm, N., Hampton, M.B. and Wallace, A.J. (2010) Individual and Combined Effects of Foods on Helicobacter pylori Growth. Phytotherapy Research 24, 1229-1233. https://doi.org/10.1002/ptr.3167 
[130] Meier, R., Wettstein, A., Drewe, J. and Geiser, H.R. (2001) Fish Oil (Eicosapen) Is Less Effective than Metronidazole, in Combination with Pantoprazole and Clarithromycin, for Helicobacter pylori Eradication. Alimentary Pharmacology \& Therapeutics, 15, 851-855. https://doi.org/10.1046/j.1365-2036.2001.00989.x

[131] Duggan, A.E., Atherton, J.C., Cockayne, A., Balsitis, M., Evison, S. and Hale, T. (1997) Clarification of the Link between Polyunsaturated Fatty Acids and Helicobacter pylori-Associated Duodenal Ulcer Disease: A Dietary Intervention Study. The British Journal of Nutrition, 78, 515-522. https://doi.org/10.1079/BJN19970171

[132] Thompson, L., Cockayne, A. and Spiller, R.C. (1994) Inhibitory Effect of Polyunsaturated Fatty Acids on the Growth of Helicobacter pylori: A Possible Explanation of the Effect of Diet on Peptic Ulceration. Gut, 35, 1557-1561. https://doi.org/10.1136/gut.35.11.1557

[133] Khulusi, S., Ahmed, H.A., Patel, P., Mendall, M.A. and Northfield, T.C. (1995) The Effects of Unsaturated Fatty Acids on Helicobacter pylori in Vitro. Journal of Medical Microbiology, 42, 276-282. https://doi.org/10.1099/00222615-42-4-276

[134] Aldoori, W.H., Giovannucci, E.L., Stampfer, M.J., Rimm, E.B., Wing, A.L. and Willett, W.C. (1997) A Prospective Study of Alcohol, Smoking, Caffeine, and the Risk of Duodenal Ulcer in Men. Epidemiology (Cambridge, Mass.), 8, 420-424. https://doi.org/10.1097/00001648-199707000-00012

[135] Jayaraj, A.P., Tovey, F.I., Lewin, M.R. and Clark, C.G. (2000) Duodenal Ulcer Prevalence: Experimental Evidence for the Possible Role of Dietary Lipids. Journal of Gastroenterology and Hepatology, 15, 610-616. https://doi.org/10.1046/j.1440-1746.2000.02214.x

[136] Ito, Y., Suzuki, K., Ichino, N., Imai, H., Sakaguchi, H. and Hokama, M. (2000) The Risk of Helicobacter pylori Infection and Atrophic Gastritis from Food and Drink Intake: A Cross-Sectional Study in Hokkaido, Japan. Asian Pacific Journal of Cancer Prevention, 1, 147-156.

[137] Petschow, B.W., Batema, R.P. and Ford, L.L. (1996) Susceptibility of Helicobacter pylori to Bactericidal Properties of Medium-Chain Monoglycerides and Free Fatty Acids. Antimicrob Agents Chemother, 40, 302-306.

[138] Fuller, R. (1989) Probiotics in Man and Animals. The Journal of Applied Bacteriology, 66, 365-378. https://doi.org/10.1111/j.1365-2672.1989.tb05105.x

[139] Gotteland, M., Brunser, O. and Cruchet, S. (2006) Systematic Review: Are Probiotics Useful in Controlling Gastric Colonization by Helicobacter pylori? Alimentary Pharmacology \& Therapeutics, 23, 1077-1086. https://doi.org/10.1111/j.1365-2036.2006.02868.x

[140] Jack, R.W., Tagg, J.R. and Ray, B. (1995) Bacteriocins of Gram-Positive Bacteria. Microbiological Reviews, 59, 171-200.

[141] Bogovic-Matijasic, B., Rogelj, I., Nes, I.F. and Holo, H. (1998) Isolation and Characterization of Two Bacteriocins of Lactobacillus acidophilus LF221. Applied Microbiology and Biotechnology, 49, 606-612. https://doi.org/10.1007/s002530051221

[142] Felley, C.P., Corthesy-Theulaz, I., Rivero, J.L., Sipponen, P., Kaufmann, M. and Bauerfeind, P. (2001) Favourable Effect of an Acidified Milk (LC-1) on Helicobacter pylori Gastritis in Man. European Journal of Gastroenterology \& Hepatology, 13, 25-29. https://doi.org/10.1097/00042737-200101000-00005

[143] Vítor, J.M. and Vale, F.F. (2011) Alternative Therapies for Helicobacter pylori: Probiotics and Phytomedicine. FEMS Immunology and Medical Microbiology, 63, 153-164. https://doi.org/10.1111/j.1574-695X.2011.00865.x

[144] Lionetti, E., Miniello, V.L., Castellaneta, S.P., Magista, A.M., de Canio, A. and Maurogiovanni, G. (2006) Lactobacillus reuteri Therapy to Reduce Side-Effects during An- 
ti-Helicobacter pylori Treatment in Children: A Randomized Placebo Controlled Trial. Alimentary Pharmacology \& Therapeutics, 24, 1461-1468. https://doi.org/10.1111/j.1365-2036.2006.03145.x

[145] Lionetti, E., Indrio, F., Pavone, L., Borrelli, G., Cavallo, L. and Francavilla, R. (2010) Role of Probiotics in Pediatric Patients with Helicobacter pylori Infection: A Comprehensive Review of the Literature. Helicobacter, 15, 79-87. https://doi.org/10.1111/j.1523-5378.2009.00743.x

[146] Lesbros-Pantoflickova, D., Corthesy-Theulaz, I. and Blum, A.L. (2007) Helicobacter pylori and Probiotics. The Journal of Nutrition, 137, 812S-818S.

[147] Miki, K., Urita, Y., Ishikawa, F., Iino, T., Shibahara-Sone, H. and Akahoshi, R. (2007) Effect of Bifidobacterium bifidum Fermented Milk on Helicobacter pylori and Serum Pepsinogen Levels in Humans. Journal of Dairy Science, 90, 2630-2640. https://doi.org/10.3168/jds.2006-803

[148] Drouin, E. (1999) Helicobacter pylori: Novel Therapies. Canadian Journal of Gastroenterology, 13, 581-583. https://doi.org/10.1155/1999/485237

[149] Broekaert, I.J. and Walker, W.A. (2006) Probiotics and Chronic Disease. Journal of Clinical Gastroenterology, 40, 270-274. https://doi.org/10.1097/00004836-200603000-00021

[150] Boltin, D. (2016) Probiotics in Helicobacter pylori-Induced Peptic Ulcer Disease. Best Practice \& Research. Clinical Gastroenterology, 30, 99-109.

https://doi.org/10.1016/j.bpg.2015.12.003

[151] Li, B.-Z., Threapleton, D.E., Wang, J.-Y., Xu, J.-M., Yuan, J.-Q. and Zhang, C. (2015) Comparative Effectiveness and Tolerance of Treatments for Helicobacter pylori: Systematic Review and Network Meta-Analysis. BMJ (Clinical Research Ed.), 351, h4052. https://doi.org/10.1136/bmj.h4052

[152] Wang, Z.H., Gao, Q.Y. and Fang, J.Y. (2013) Meta-Analysis of the Efficacy and Safety of Lactobacillus-containing and Bifidobacterium-Containing Probiotic Compound Preparation in Helicobacter pylori Eradication Therapy. Journal of Clinical Gastroenterology, 47, 25-32. http://dx.doi.org/10.1097/MCG.0b013e318266f6cf

[153] Hongying, F., Xianbo, W., Fang, Y., Yang, B. and Beiguo, L. (2014) Oral Immunization with Recombinant Lactobacillus acidophilus Expressing the Adhesin Hp0410 of Helicobacter pylori Induces Mucosal and Systemic Immune Responses. Clinical and Vaccine Immunology, 21, 126-132. https://doi.org/10.1128/CVI.00434-13

[154] Tong, J.L., Ran, Z.H., Shen, J., Zhang, C.X. and Xiao, S.D. (2007) Meta-Analysis: The effect of Supplementation with probiotics on Eradication Rates and Adverse Events during Helicobacter pylori Eradication Therapy. Alimentary Pharmacological Therapy, 25, 155-168.

[155] Zou, J. and Dong, J. (2009) Yu Lactobacillus Containing Quadruple Therapy versus Standard Triple First-Line Therapy for Helicobacter pylori Eradication. Helicobacter, 14, 97-107. https://doi.org/10.1111/j.1523-5378.2009.00716.x

[156] Sachdeva, A. and Nagpal, J. (2009) Effect of Fermented Milk-Based Probiotic Preparations on Helicobacter pylori Eradication: A Systematic Review and Meta-Analysis of Randomized-Controlled Trials. European Journal of Gastroenterology \& Hepatology, 21, 45-53.

[157] Szajewska, H., Horvath, A. and Piwowarczyk, A. (2010) Meta-Analysis: The Effects of Saccharomyces boulardii Supplementation on Helicobacter pylori Eradication Rates and Side Effects during Treatment. Alimentary Pharmacology \& Therapeutics, 32, 1069-1079. https://doi.org/10.1111/j.1365-2036.2010.04457.x

[158].Zheng, Y., Lu, Y., Wang, J., Yang, L., Pan, C. and Huang, Y. (2013) Probiotic Properties of Lactobacillus Strains Isolated from Tibetan Kefir Grains. PloS One, 8, e69868. 
https://doi.org/10.1371/journal.pone.0069868

[159] Gong, Y., Li, Y. and Sun, Q. (2015) Probiotics Improve Efficacy and Tolerability of Triple Therapy to Eradicate Helicobacter pylori: A Meta-Analysis of Randomized Controlled Trials. International Journal of Clinical and Experimental Medicine, 8, 6530-6543.

[160] Dang, Y., Reinhardt, J.D., Zhou, X. and Zhang, G. (2014) The Effect of Probiotics Supplementation on Helicobacter pylori Eradication Rates and Side Effects during Eradication Therapy: A Meta-Analysis. PloS One, 9, Article ID: e111030.

https://doi.org/10.1371/journal.pone.0111030

[161] Zhu, R., Chen, K., Zheng, Y.-Y., Zhang, H.-W., Wang, J.-S. and Xia, Y.-J. (2014) Meta-Analysis of the Efficacy of Probiotics in Helicobacter pylori Eradication Therapy. World Journal of Gastroenterology, 20, 18013-18021.

[162] Zhang, M.-M., Qian, W., Qin, Y.-Y., He, J. and Zhou, Y.-H. (2015) Probiotics in Helicobacter pylori Eradication Therapy: A Systematic Review and Meta-Analysis. World Journal of Gastroenterology, 21, 4345-4357. https://doi.org/10.3748/wjg.v21.i14.4345

\section{Submit or recommend next manuscript to SCIRP and we will provide best service} for you:

Accepting pre-submission inquiries through Email, Facebook, LinkedIn, Twitter, etc.

A wide selection of journals (inclusive of 9 subjects, more than 200 journals)

Providing 24-hour high-quality service

User-friendly online submission system

Fair and swift peer-review system

Efficient typesetting and proofreading procedure

Display of the result of downloads and visits, as well as the number of cited articles

Maximum dissemination of your research work

Submit your manuscript at: http://papersubmission.scirp.org/

Or contact aim@scirp.org 